Check for updates

Cite this: Mater. Chem. Front., 2020, 4, 2863

Received 15th June 2020

Accepted 16th July 2020

DOI: $10.1039 / \mathrm{d} 0 \mathrm{qm} 00398 \mathrm{k}$

rsc.li/frontiers-materials

\section{Role of interface properties in organic solar cells: from substrate engineering to bulk-heterojunction interfacial morphology}

\author{
Hong Zhang, ${ }^{a}$ Yanxun Li, ${ }^{a}$ Xuning Zhang, ${ }^{b}$ Yuan Zhang ${ }^{b}{ }^{b}$ and Huiqiong Zhou (D) *a \\ The performance of organic solar cells (OSCs) depends on a fine, carefully optimized bulk- \\ heterojunction $(\mathrm{BHJ})$ microstructure. The understanding and manipulation of $\mathrm{BHJ}$ morphology have \\ been the focus of research in optoelectronic devices. In this article, recent advances in understanding \\ and controlling the $\mathrm{BHJ}$ morphology via substrate engineering and $\mathrm{BHJ}$ active layer processing are \\ reviewed. From the chemical and physical surface structure of substrates, we reviewed the active layer \\ morphology depending on the nature of the substrate and the deposition conditions, and it can also be \\ controlled to change the blend-substrate interface by changing the surface properties of the substrate. \\ We also reviewed the effect of solvent (co-solvent and solvent additive) and post-treatment (thermal \\ annealing and solvent vapor annealing) on the evolution kinetics of the film, which helps to form the \\ optimal percolation path and thus provides a simple way to improve photovoltaic performance. Since \\ the interaction between intermolecules is weak, the sensitive assembly of molecules depends on fining \\ miscibility between the components in the $\mathrm{BHJ}$ active layer. Starting from the processing conditions of \\ the substrate and the active layer can greatly control the morphology of $\mathrm{BHJ}$, and provide future \\ research directions for OSCs.
}

\section{Introduction}

In the past 30 years, organic semiconductors, as an emerging electronic and optoelectronic material, have shown great potential for the next generation of flexible solar cells. The rise of organic solar cells (OSCs) is due to their solutionprocessability, flexible manufacturing and potential toward high-throughput, large-area, roll-to-roll fabrication. ${ }^{1-4}$ Since 2000 , the efficiency of OSCs has increased dramatically (from about $2 \%$ to $18 \%),{ }^{5-11}$ largely driven by the optimization of energy levels to maximize light absorption and minimize energy and recombination losses from the heterojunction and interface. Although the laboratory efficiency of OSCs has reached $17 \%, 6,7,12,13$ totally matching with traditional siliconbased solar cell modules, in large-scale industrial fabrication, low power conversion efficiency (PCE) and stability are both major barriers to commercialization. Driven by the potential for large-scale fabrication, developing a stable process for large area coatings with high average efficiencies and reliability remains a major challenge for the organic photovoltaic technology. ${ }^{3,14-16}$

\footnotetext{
${ }^{a}$ CAS Center for Excellence in Nanoscience, National Center for Nanoscience and Technology, Beijing 100190, P. R. China. E-mail: zhouhq@nanoctr.cn

${ }^{b}$ School of Chemistry, Beijing Advanced Innovation Center for Biomedical Engineering, Beihang University, Beijing 100191, P. R. China
}

From the molecular conformation and crystallinity to the operating region scale of the device, the electronic properties of solution-based processing thin films are highly sensitive to the morphological characteristics during deposition. ${ }^{17-19}$ Therefore, the main issue discussed in solution-based processing OSCs is the development of methods for forming organic semiconductor thin films with uniform and well-oriented morphology.

Organic molecular assembly and thin film morphology control are key challenges in the development of common solution-based processing techniques. ${ }^{18,20-22}$ The significance of these challenges lies in the fact that charge transport, separation and recombination in OSCs is highly sensitive to morphological parameters of thin films across all length scales, which include paracrystalline size at the nanoscale, domain percolation at the mesoscale, and domain alignment and boundary distribution at the macroscale. ${ }^{19,20,23}$ Currently, the layer-by-layer (LbL) solution processing approach is an option to construct a pseudo-bilayer configuration for optimal active layer morphology. ${ }^{24}$ However, the bulk-heterojunction (BHJ) approach has taken an irreplaceable lead in the development of OSCs, and morphology control of the active layer in BHJ solar cells is an essential consideration that could improve PCE. We, therefore, focus on the BHJ morphology control in this review. The $\mathrm{BHJ}$ active layer usually consists of an interpenetrating 
network of electron-donating conjugated polymers and electronaccepting fullerenes (or non-fullerenes molecules). ${ }^{25-28}$ Important factors that must be considered when optimizing the morphology of the $\mathrm{BHJ}$ active layer include (a) miscibility between donor and acceptor (D-A) materials; ${ }^{29,30}$ (b) semi-crystalline characteristics of phase-separated domains; ${ }^{31,32}$ and (c) vertical concentration gradient. $^{33}$ In solution-based processing OSCs, processing also allows the free control of phase separation and molecular self-organization during solvent evaporation and/or film treatment. $^{4,34,35}$ Because the morphology of $\mathrm{BHJ}$ is frozen dynamically during the rapid evaporation of the solution, ${ }^{28,36}$ it is difficult to predict the final morphology of films from the blend solution. The importance of surface property control in determining the performance of solution-based solar cells is emphasized. ${ }^{37,38}$ The surface energy of the solution is one that establishes the film-forming environment, which has a predictable effect on the final film-forming morphology. ${ }^{39-41}$ During the formation of droplets, such as spray or blow drying, the size of the droplets formed is a function of the surface energy. ${ }^{42}$ In particular, in polymers, many polymers have low surface energy and processes such as ink printing do not work well because the ink does not wet the polymer surface. Surface energy will play a role in any surface interaction between the polymer and the fluid. It will determine the degree of wettability, the ease with which fluids enter the fibrotic region, and, to some extent, the energetics of fluid-polymer interactions. ${ }^{42,43}$ Specifically, surface energy control is the most promising way to achieve suitable D-A separation for high-performance OSCs. Vertical phase separation could be induced by controlling the surface energy owing to the attraction between molecules having a similar surface energy. ${ }^{4,45}$ In the solution-based deposition of polymers and solvents, there may be multiple grain boundary configurations between randomly combined particles. Since the orientation of some grains is more energetic than that of others, the contact grains rotate or rearrange to reduce their grain boundary energy. ${ }^{46}$ In addition, the range of solid-vapor surface energy comes from the range of crystal surface orientation. For liquids, the amount of surface energy increases, including grain boundaries, solid-vapor, liquid-vapor and solid-liquid combinations. Polymer fibrillar components can determine the morphological framework of the network structure, which is very beneficial for $\mathrm{BHJ}$ OSCs. A possible route to $\mathrm{BHJ}$ formation is shown in Fig. 1 where the morphological framework of the network structure is initiated by surface property control. Dynamic wetting is a fundamental feature of solution-based processes, such as coating and printing. Because of its practical importance, numerous studies of dynamic wetting have been conducted over the past few decades. Both macroscale (hydrodynamic) and microscale (molecular-kinetic) theories exist to explain the mechanics near the dynamic contact line. To date, the issue is still debated, as discussed in other reviews. ${ }^{47}$ Although the exact mechanism of morphology is under debate, there is, actually, a lack of relationship between the nanomorphology of the BHJ film to the surface energy. As discussed by Diao et al. in their review, ${ }^{48}$ physics insights into the role of surface energy effects were described. Most of the work at present is likely to

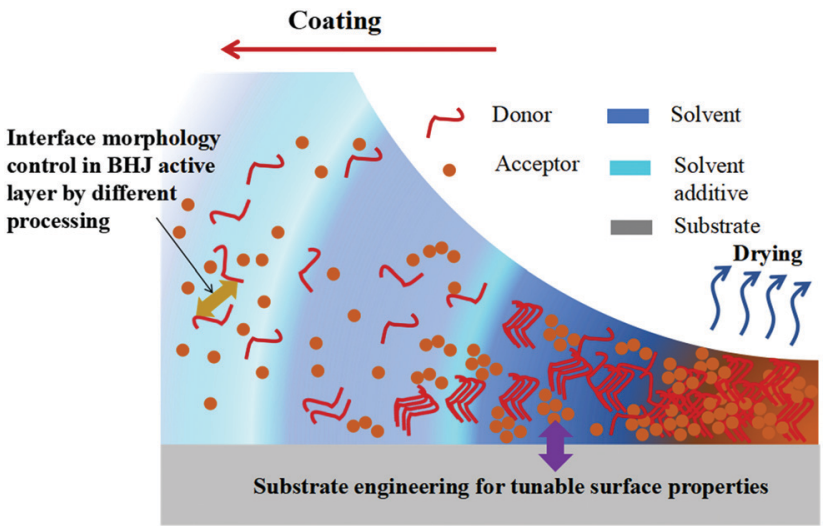

Fig. 1 A schematic showing a possible route to formation of the $\mathrm{BHJ}$ morphology during deposition, which depends on the nature of the substrate and the evolution deposition conditions of the film.

focus on a relevant morphological control strategy for a variety of optoelectronic technologies that build on the processability of organic semiconductors. ${ }^{48-51}$

In this review, we provide more details of the morphologysurface energy relationship for OSCs, putting it into context with other morphology control strategies. From substrate engineering and interface morphology controlled in a $\mathrm{BHJ}$ active layer, we present the current understanding of how surface properties control impact phase separation, enabled by recent advances in in situ morphology characterization. We summarize how such a substrate induces changes in the morphology of the active layers; understanding how such solvent additives and post-treatment affect film formation has prompted their use in solution-processed organic photovoltaic technologies. This summarizes the effects of surface properties on substrates and introduces various morphological control strategies for optoelectronic technologies. Finally, this review looks forward to the fine control of BHJ morphology that can be achieved by fine-tuning the surface properties of the substrate and the weak interaction of each component in the active layer system, thus providing a potential strategy for the future development of OSCs.

\section{Morphology optimization for organic photovoltaics}

\subsection{Miscibility of donors and acceptors}

The efficiency and stability of OSCs are two key factors of limiting the industrial development of devices. These two factors are mainly influenced by the molecular morphology of the $\mathrm{BHJ}$ active layer. The basic working principles in OSCs are schematically illustrated in Fig. 2, with four subsequent processes to generate photocurrent: (1) organic layers absorb incident photons to generate electron-hole pairs (excitons); (2) excitons diffuse towards the donor-acceptor interface; (3) excitons dissociate by charge transfer at the D-A interface; (4) holes and electrons transport in donor and acceptor layers, and are collected at the electrodes. 


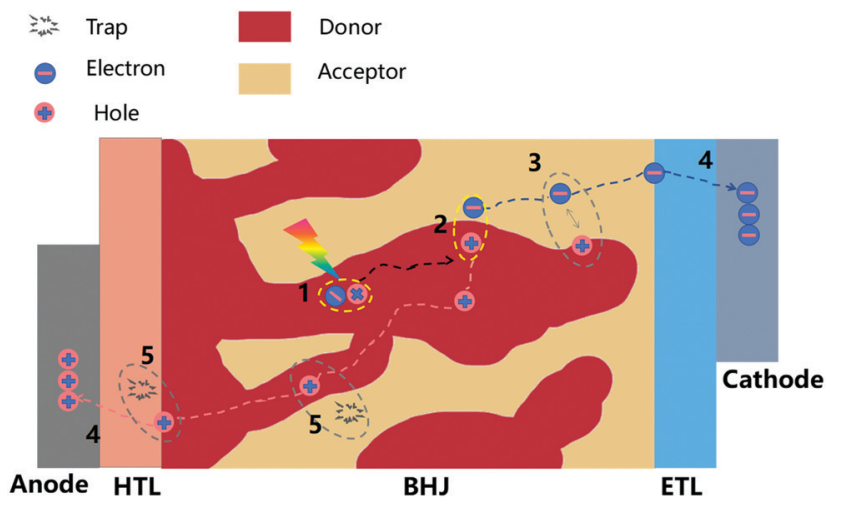

Fig. 2 Working principles of BHJ OSCs: (1) exciton generation under illustration; (2) excitons diffuse; (3) excitons dissociate at the D-A interface; charge transportation; (4) charge extraction and (5) charge recombination.

Many studies have shown that polymer-fullerene BHJs are composed of a mixture of pure polymer, pure fullerene and disordered polymer and fullerene components. ${ }^{52-55}$ Because OSCs operate via separation of a short-lived exciton at a donor/acceptor interface, the PCE of the system is closely related to the morphology of active layers and the relationship between these three phases (pure polymer, pure fullerene and disordered polymer and fullerene components). As shown in Fig. 3, on one hand, the blends create a network of bicontinuous phase separation materials, providing a maximum discrete interface area, separating excitons into free charge. On the other hand, the mixed-phase is considered counterproductive

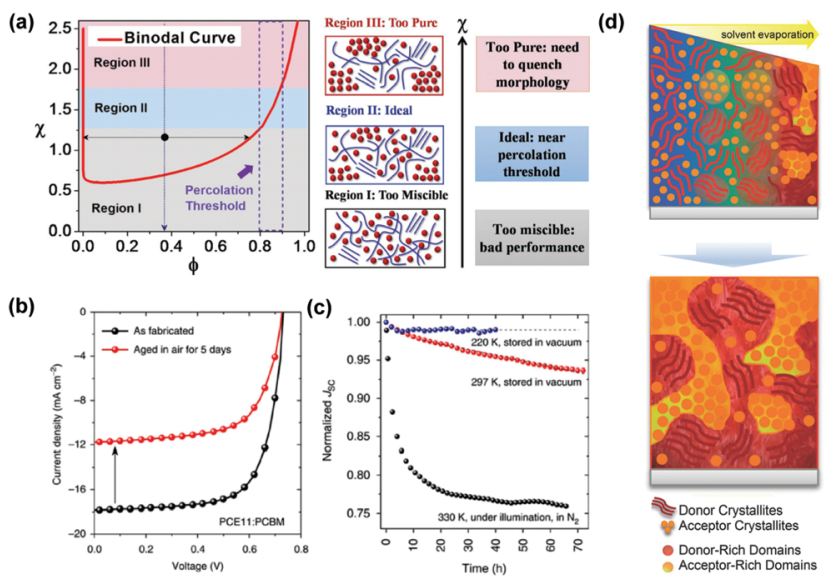

Fig. 3 (a) Schematic diagram of the three states in the $\chi-\varphi$ phase diagram. Regions I, II, and III represent high $\chi$, medium $\chi$ and low $\chi$, respectively. The dashed rectangle indicates the reported percolation threshold with a polymer volume fraction of 0.8-0.9. Reproduced with permission. $^{29}$ Copyright 2018, Wiley-VCH Verlag GmbH \& Co. KGaA. (b) J-V characteristics of optimized PffBT4T-2OD:PCBM devices measured after fabrication (fresh) and after being aged in air for 5 days (aged). (c) Evolution of $J_{s c}$ of optimized devices measured at different temperatures. Reproduced with permission. ${ }^{56}$ Copyright 2017, Nature Publishing Group. (d) Schematic diagram showing possible ways to form $\mathrm{BHJ}$ morphology during deposition. Reproduced with permission. ${ }^{70}$ Copyright 2018, Wiley-VCH Verlag GmbH \& Co. KGaA. to device performance because the separated molecules can act as traps for separating charges. Thus, donor-acceptor miscibility is a demonstrably important material property, which governs the formation of the charge collection pathways within BHJ devices. In terms of the stability of OSCs, miscibility between donor and acceptor materials has a strong influence on an abnormal strong burn-in degradation. ${ }^{56}$ The spinodal demixing of the donor and acceptor leads to abnormally strong aging degradation, which greatly reduces charge generation, which can be attributed to the inherent low miscibility of donors and acceptors. Although microstructure can be dynamically tailored for high performance, the inherent low miscibility of the donor and acceptor results in spontaneous phase separation in the solid-state. As shown in Fig. 3a, high miscibility leads to the formation of ultrapure domains, which increases bimolecular recombination and reduces the shortcircuit current density $\left(J_{\mathrm{sc}}\right)$ and fill factor (FF) of devices. By contrast, too little miscibility leads to intense burn-in degradation of donor-acceptor devices, such as polymer PffBT4T2OD. From a positive in-depth investigation, the Flory-Huggins interaction parameter $\chi$ was calculated by the melting-point depression method, proving that FTAZ and PDPP3T of the two polymers were completely miscible. The use of the FloryHuggins interaction parameter could quantitatively describe the degree of miscibility between two components. ${ }^{57}$ As shown in Fig. 3a, when the crystallization of PCBM is kinetically inhibited during device fabrication, the dihedral composition along the $\chi-\varphi$ phase diagram coexistence curve determines the maximum purity obtainable in the amorphous mixed phase. It is worth noting that the quantification of temperaturedependent miscibility also confirmed Flory-Huggins $\chi(T)$ for an amorphous and crystalline polymer system. ${ }^{58}$ Thermodynamic interactions of key constituent materials will enable us to establish relationships between their thermodynamic morphology and properties in actual OSCs. In OSCs with the non-fullerene field, hundreds of non-fullerene small molecule acceptors have replaced fullerene acceptors, and the effect of miscibility needs to be further studied. ${ }^{59-65}$ Miscibility/ $\chi$-function relationships were performed on some nonfullerene OSCs, all of which pointed to a similar trend that high $\chi$ is a prerequisite for high purity of the domain, and therefore may be high FF in devices. ${ }^{66}$ In particular, researchers have recognized the importance of miscibility in ternary OSCs, such as the distribution of the kinds of third additive on the interface between the donor and acceptor. ${ }^{67-69}$

\subsection{Paracrystalline characteristics of phase-separated domains}

In OSCs, paracrystalline conjugated polymers typically have relatively strong intramolecular and intermolecular interactions, such as vis-à-vis $\pi$-interactions and hydrogen bonding under certain conditions, ${ }^{71}$ such that polymers may already be aggregated in solution during deposition. ${ }^{72}$ In such cases, the entropy barrier accumulated during the supersaturation process is eliminated, making the whole crystallization process different from those of traditional non-conjugated polymers. ${ }^{71}$ Although there are regional 
differences, this "ideal" OSC morphology usually includes phase separation in the range of $\sim 10 \mathrm{~nm}$ to match the typical exciton diffusion length between a pure donor and an acceptor phase. ${ }^{73}$ In addition, the "ideal" donor and acceptor networks have perfect connections to the anode and cathode, respectively, possibly through the straight electrode. On the other hand, direct control of the orientation of the polymer chains relative to the direction of carrier transport allows the active layer to have good properties. ${ }^{74,75}$ The alignment of the polymer chains in a particular planar direction facilitates charge transfer because charge transfer along the polymer backbone is faster. Studies on controlling the planar orientation of polymer semiconductors have focused on chemical modification and side-chain chemistry to control the surface energy of conjugated polymers. ${ }^{75,76}$

\subsection{The presence of percolating charge transport networks}

In OSCs, the size of the phase separation domain is one of the most important morphological characteristics to determine the exciton capture efficiency, which has a profound impact on the device performance. ${ }^{32}$ Unlike inorganic semiconductors, due to the low permittivity of organic materials, light absorption in OSCs produces coulomb-bound excitons rather than freecharge carriers. The dissociation of the charge requires the subsequent collection of the electrode, which requires the diffusion of the exciton to a boundary between the donor and acceptor domains, resulting in photocurrent. Therefore, solution-based processing techniques that can control the donor and acceptor domain morphology for percolating charge transport networks to some extent is a key tool to achieve high-performance devices.

In solutions containing two components, such as semiconductor polymers and fullerene derivatives, various phase separation processes such as liquid-liquid (L-L) phase separation and solid-liquid (S-L) phase separation may occur simultaneously when the solvent dries. The fast quenching of the solvent leads to a non-equilibrium state. Therefore, the evolution of films is a rather complicated process, in which thermodynamic and kinetic parameters play an important role. ${ }^{77,78}$ The transient bilayers formed by the polymer wetting process are unstable and subsequently decompose and diffuse up to dewetting lateral domains. ${ }^{42}$ These processes and processing conditions determine the final morphology of the blend film. It is an effective way to promote the charge extraction and reduce the charge recombination of the photoactive layer by using the $\mathrm{BHJ}$ film with a vertical component gradient, especially donor-enriched at the anode and acceptorenriched at the cathode. The establishment of a vertical component gradient of binary blends in the early stage of film formation can be explained by the occurrence of surface-oriented spinodal decomposition, which induces a component of the blend to migrate to the surface of the film. ${ }^{33}$

\section{Substrate engineering for tunable surface properties}

As discussed in the previous section, the blend morphology at the micro/nanoscopic scale is a key factor determining the efficiency of BHJ solar cells. A common challenge in organic semiconductor deposition is to overcome the surface dewetting problems that lead to poor film uniformity or low substrate coverage. ${ }^{79,80}$ It has been widely reported that the chemical and physical surface structure of substrates may affect the nucleation of the molecule, thereby affecting the bulk film morphology due to the variation in the composition of the active layer. One of the most common strategies for controlling the wettability of the substrate is to treat it with ozone ${ }^{81}$ or argon plasma, ${ }^{82}$ which leads to an increase in surface hydrophilicity, which is usually necessary to ensure solution wettability. This effect is determined by the surface energy, surface morphology and surface dynamics. Among them, the three characteristics interact with each other and the surface energy can be visually reflected. In this section, therefore, we have reviewed the current state of understanding concerning tunable surface properties, giving examples of substrate engineering that have been observed in OSCs.

\subsection{Surface energy effects}

The presence of solid/liquid substrates, free surfaces, and other heterogeneities can affect the crystallization of the active layer material in a number of ways. ${ }^{83,84}$ In crystal dynamics, heterogeneous nucleation occurs in the same manner as homogeneous nucleation, but the heterogeneous nucleation of the Gibbs free energy barrier is lower (occurring at a faster rate). Thus, heterogeneous nucleation dominates in systems where surface, defects, and impurities are readily available. For nucleation onto the surface, the contact region of forming a new surface is reduced and now depends on the free energy of the interface between the substrate, liquid and cluster. ${ }^{85}$ The interface free energy term depends on the system geometry and wettability of the solute clusters on the substrate described by the contact angle. These properties depend on the chemistry of the surface groups and the paired molecular interactions between the surfaces, nucleating clusters, and solvents. The interaction strength (surface energy) of the substrate/organic semiconductor is the importance of nucleation, which is directly derived from classical nucleation theory. Therefore, it has become a widespread study to study and use self-assembled monolayers (SAMs) and other "buffer layers" to obtain good mesoscale or nanoscale molecular ordering. Kim et al. ${ }^{86}$ studied the role of SAM functionalized with various groups $\left(-\mathrm{NH}_{2},-\mathrm{OH}\right.$, and $\left.-\mathrm{CH}_{3}\right)$ at the interface between P3HT and the insulator substrate $\left(\mathrm{SiO}_{x}\right)$. Using grazing incidence X-ray diffraction (GIXRD), they found that depending on the properties of the substrate surface, the P3HT nanocrystals have two different orientations, parallel and perpendicular, to the insulator substrate. The field-effect mobility of two different orientations differs by more than a factor of 4 .

For better wetting (lower contact angles), the nucleation barrier is inhibited much more. Unlike small molecules, if the polymer chains are incorporated into a perfect crystal, their conformational change (expansion) tends to take less time than the crystallization. Therefore, polymers often produce chainfolded domains (lamellae) surrounded by amorphous regions, 
and the presence and degree of chain-folding are sensitive to the rigidity of the polymer. ${ }^{87,88}$ According to an evolutive Hoffman-Lauritzen theory, ${ }^{89}$ the crystal growth rates on flexible polymers are controlled by surface nucleation; during the polymer deposition process, a new, atomically smooth growth front is formed on the growth surface chain, which is waiting for further nucleation.

The use of surface treatment to control the direction of polymer accumulation is particularly important for optoelectronic devices, where the transfer of charge perpendicular to the substrate is critical. ${ }^{91,92}$ As shown in Fig. 4a, Zhang et al. ${ }^{41}$ found that substrate surface energies dictate the thin film morphology by modulating the free energy barrier to heterogeneous nucleation. There is a relationship: the lower the substrate surface energy, the lower the $\Delta G_{\mathrm{A}}$ and therefore the free energy barrier to nucleation. Meng et al., ${ }^{93}$ also reported that a cross-linkable donor polymer PTB7-TV was synthesized and applied as a morphology-inducing layer. With PTB7-TV spin-coated on poly(3,4-ethylenedioxythiophene)-poly(styrenesulfonate) (PEDOT:PSS), the much smaller surface energy of the underlying layer leads to improved vertical composition profile and reduced phase separation domain size in the active layer. Huang et al., ${ }^{90}$ further studied the relationship between the surface energy of the interfacial material and vertical stratification profile of the $\mathrm{BHJ}$. They reported that the desired vertical stratification profile can be established by employing interfacial materials with desirable surface energy, and the $J_{\text {sc }}$ can be directly modulated by the vertical stratification. By mixing ZnO nanoparticles with PFN-Br, Zheng et al., ${ }^{94}$ developed a

(a)
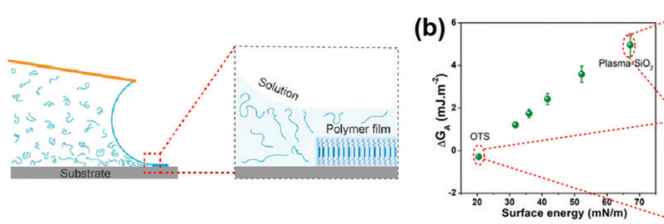

(c)

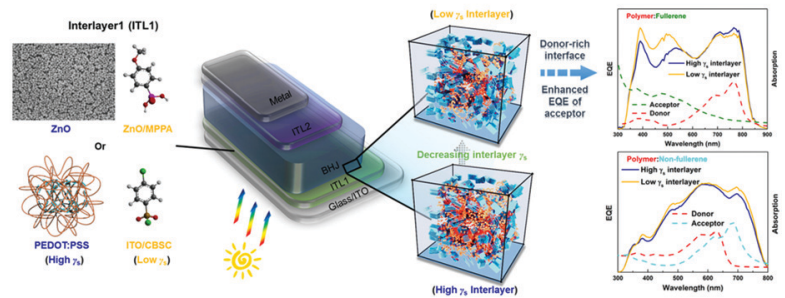

Fig. 4 Free energy modeling of surface-energy-dependent excess free energy per surface area, $\Delta G_{A}$. (a) Schematic of the conjugated polymer crystallization process during meniscus-guided coating. (b) Substrate surface energy-dependent $\Delta G_{A}$ and illustration of thin-film morphology (in-plane) comparing OTS and plasma-treated substrates. Alkyl chains are omitted from the illustration to highlight the change in crystallite domain size, degree of crystallinity, and alignment. Reproduced with permission. ${ }^{41}$ Copyright 2018, American Chemical Society. (c) Modification of the surface energy of the substrate can be achieved using a self-assembly interface modification, which in turn directly affects the ratio of polymer donor to acceptor at the interface. Surface energy optimizes vertical stratification to improve the final photoelectric conversion performance. Reproduced with permission. ${ }^{90}$ Copyright 2018, American Chemical Society. systematic adjustment of the surface free energy of a continuously graded $\mathrm{ZnO}$ electron transport layer from $51.23 \mathrm{mN} \mathrm{m}^{-1}$ to $76.62 \mathrm{mN} \mathrm{m}^{-1}$. The electron transport layer with a surface free energy of $63.89 \mathrm{mN} \mathrm{m}^{-1}$ can optimize the bulk heterojunction morphology. In tandem solar cells, the incorporation of self-organized material will further simplify the procedure of device fabrication. Kang et al., ${ }^{95}$ applied polyethyleneimine (PEI) to attain a simplified four-layer tandem structure and a high tandem-PCE approaching 11\%.

Chen et al. ${ }^{90}$ have proposed that donor or acceptor material can be selectively enriched at the $\mathrm{BHJ} /$ substrate interface through tuning the surface energy offset between the interface and active materials. As exhibited in Fig. 5a-c, in Zheng and co-workers' work, $\mathrm{WO}_{x}$ nanoparticles have been incorporated in PEDOT:PSS to tune the surface energy of the hole transport layers (HTLs). ${ }^{97}$ Benefiting from the optimal surface energy, the PCE of OSCs has achieved large enhancement and the FF can be up to $80 \%$. As illustrated in Fig. $5 \mathrm{~d}$ and e, the surface energy of HTLs has been regulated via incorporating poly(styrene sulfonic acid) sodium salt (PSSS) or nickel formate dihydrate (NFD) in PEDOT:PSS by Wang and co-workers. Through tuning the concentration of PSSS or NFD, the surface energy can be tuned in a large range from $36.51 \mathrm{mN} \mathrm{m}^{-1}$ to $77.56 \mathrm{mN} \mathrm{m}^{-1}$. Further relationship between the orientation of $\mathrm{BHJ}$ and the surface energy of the HTLs has been proposed in this work. It has been concluded that the face-on orientation-preferred BHJs favor HTLs with higher surface energy while the edge-on orientation preferred BHJs are partial to HTLs with lower energy. ${ }^{98}$

As mentioned before, an important parameter for the performance of OSCs is the phase separation and crystallinity of the donor and acceptor domains. When a chemical agent with low surface energy (such as a hydrocarbon solvent or detergent) is dropped into a medium with high surface energy (a)

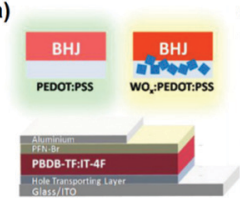

(d)

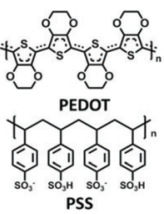

(b)

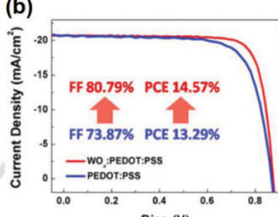

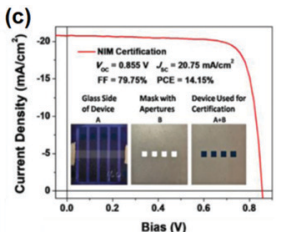

(e)

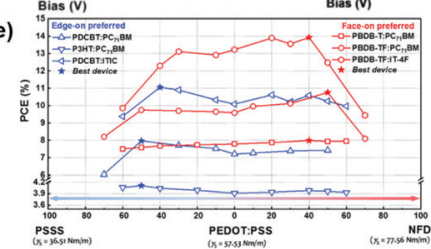

Fig. 5 (a) Schemes of the OSC device structure and the incorporation of $W_{x}$ nanoparticles into PEDOT:PSS. (b) $J-V$ characteristics of the best OSC devices with and without $\mathrm{WO}_{x}$ nanoparticles. (c) Certification result of the device with WO $_{x}$ :PEDOT:PSS HTL. Reproduced with permission. ${ }^{96,97}$ Copyright 2018, Wiley-VCH. (d) Chemical structures of PEDOT, PSS, PSSS and NFD. (e) PCEs of devices with various BHJs with edge-on preferred or face-on preferred molecular orientation versus gradient tuning $\gamma_{s}$ 's of modified PEDOT:PSS HTLs. Reproduced with permission. ${ }^{98}$ Copyright 2019, Wiley-VCH. 
(for example, water), a local surface tension gradient occurs at the boundary between the surrounding materials, causing the surficial flow to a region with high surface tension. ${ }^{99-101}$ To obtain the desired electronic properties of the conjugated material, it is necessary to highly control the assembly of the polymer chain from the disordered state in the solution to the crystalline film. ${ }^{102}$ This can be achieved by the LangmuirBlodgett technique ${ }^{103}$ in which a typical amphiphilic solution is spread on the water surface to form a $2 \mathrm{D}$ monolayer at the air/water interface. The monolayer can be transferred to the substrate by perpendicular dipping (or immersing) the substrate relative to the water surface. In addition, the ordered pattern of gold and silver nanoparticle stripes can be formed spontaneously, when dewetting a dilute film of polymer-coated nanoparticles floats on the water surface. ${ }^{104}$ In this process, a drop of the solution containing the active layer material is dropped on the water substrate and spread due to the difference in surface tension (Marangoni flow). ${ }^{105,106}$ The wetting behavior depends on the spreading coefficient $S$, where $S=\gamma_{1}-\gamma_{2}-\gamma_{12}\left(\gamma_{1}\right.$ and $\gamma_{2}$ are the surface tensions of the base and polymer solutions, respectively, and $\gamma_{12}$ is the interfacial surface tension of the two solutions). ${ }^{99,107}$ The interfacial surface tension of the two solutions reflects the difference between the intermolecular forces in the bulk liquid and the intermolecular forces between the liquids. When the surface tension of the organic solvent is not very high, the spreading factor will be positive, which means that the liquid will spread (in Fig. 6b). For example, the spreading coefficient of chloroform is $12.4 \mathrm{mN} \mathrm{m}^{-1}$ and chlorobenzene is $0.6 \mathrm{mN} \mathrm{m}^{-1}$. ${ }^{107}$ Based on the spontaneous spreading (SS) phenomenon, Noh et al. ${ }^{99}$ fabricated OSCs from a mixture of polymer and fullerene derivatives on an aqueous substrate, and the device exhibited an efficiency of $8.44 \%$. This method makes it easy to control the thickness of the film by tailoring the spreading conditions. In addition, the controlled Marangoni flow and ultra-fast removal of the solvent during this process gives the film a uniform, high-quality morphology with a finely separated phase domain. As shown in Fig. 6, to fabricate top-down transmission electron microscope (TEM) samples, they found a more uniformly formed nanomorphology of the SS-PTB7: $\mathrm{PC}_{71} \mathrm{BM}$ film with finely dispersed phase separation between the $\mathrm{PTB} 7$ and $\mathrm{PC}_{71} \mathrm{BM}$ domains. Meanwhile, grazing incidence wide-angle X-ray scattering (GIWAXS) also demonstrates enhanced crystallisation and orientation of molecules during SS diffusion. Furthermore, the method can easily be transformed into the non-orthogonal solvents for the processing of bilayer devices. Janssen et al. ${ }^{108}$ fabricated bilayer-ternary OSCs with a PCE of $5.9 \%$ using spontaneous spreading on a water surface. For the PDPP2T-TT:PCBM system, the photovoltaic properties of the layer deposited by SS diffusion are comparable to the photovoltaic performance of the spin coating. For non-fullerene organic solar cells, Zhou et al., ${ }^{101}$ also fabricated non-fullerene active layer films of PDBD-T:ITIC and PBDB-T-2F:IT-4F via a similar method. Furthermore, the solar modules containing 4 -sub cells with the active area of $3.2 \mathrm{~cm}^{2}$ are also fabricated via this method, which demonstrates that spontaneous spreading on (a)

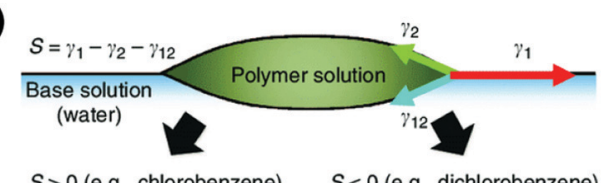

(b)
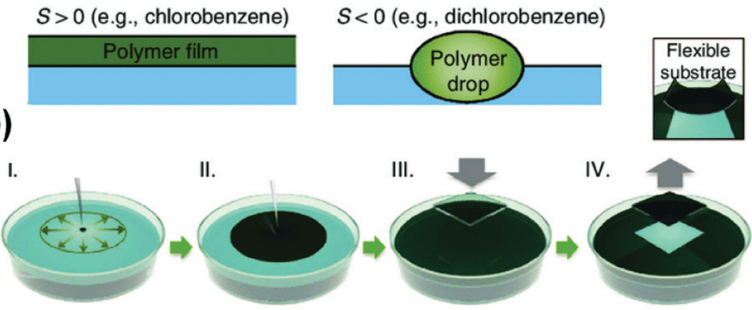

(c)
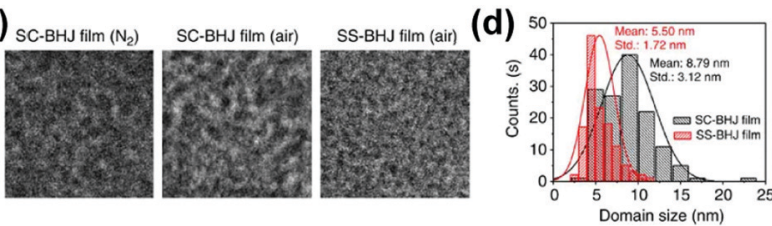

(e)
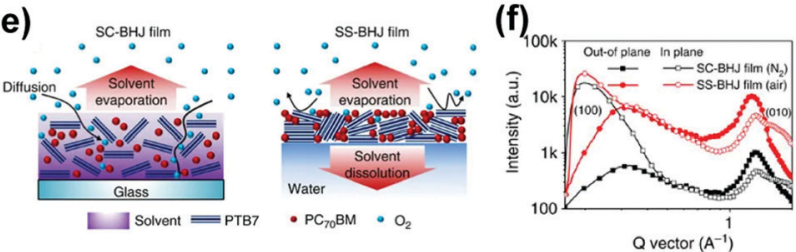

Fig. 6 (a) Spreading of polymer solution dropped onto the base solution is determined by the spreading coefficient, $S$. Positive $S$ results in a uniform polymer film; otherwise, polymer drops aggregate; (b) schematic illustrations of the formation of an SS BHJ film on the water and transfer to target substrates; (c) TEM images of $\mathrm{N}_{2}$ processed and air-processed SC-BHJ and air-processed SS-BHJ films measured at the same defocusing distance. (d) PTB7 domain size distribution histograms of $\mathrm{N}_{2}$-processed $\mathrm{SC}-\mathrm{BHJ}$ and SS-BHJ films. (e) SC-BHJ and SS-BHJ films immediately after the film formation process. (f) Out-of-plane and in-plane GIWAXS profiles of $\mathrm{SC}-\mathrm{BHJ}$ and SS-BHJ films. Reproduced with permission. ${ }^{99}$ Copyright 2016, Nature Publishing Group

aqueous surfaces is an interesting method to fabricate unconventional device architectures, with good performance.

\subsection{Surface morphology effect}

The morphology and topology of the underlying surface play many roles in organic semiconductor assembly. In recognition of surface morphology and topology, researchers often used highly regular SAMs to present a smooth and uniformly assembled substrate. In contrast, substrate morphology and SAM domain size are intentionally introduced to regulate nucleation via roughness changes. ${ }^{109}$ For instance, the structure of the underlying substrate can greatly influence the assembly of organic molecules. Steudel et al. ${ }^{110}$ introduced the influence of the roughness of the dielectric on the mobility of pentacene transistors and attributed this effect to the hindering of the movement of charges by the roughness valleys. Stadlober et al. ${ }^{111}$ showed submonolayer pentapentene films deposited on different roughness substrates via vapor deposition. When the substrate roughness is $0.25 \mathrm{~nm}$ or less, the grain area is negatively correlated with the surface roughness. While the nucleation density increases with the roughness. The authors 


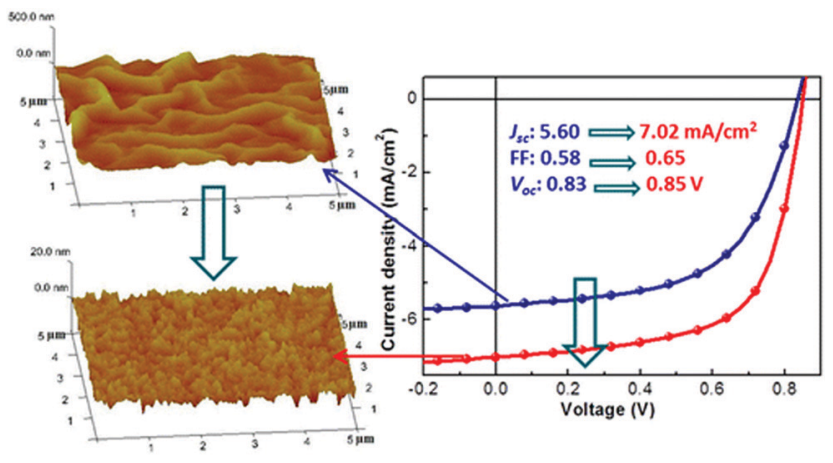

Fig. 7 Influences of surface roughness of the $\mathrm{ZnO}$ electron transport layer on the photovoltaic performance of organic inverted solar cells. Reproduced with permission. ${ }^{113}$ Copyright 2012, American Chemical Society.

attribute the latter phenomenon to an increase in the number of surface defects that act as very active nucleation sites. Many researchers have observed a significant decrease in the mobility of carriers when thin films are produced on substrates exceeding the critical roughness. Lee et al., ${ }^{112}$ investigated the effect of the reflectivity and surface roughness of various metal cathodes on the PCE of OSCs fabricated with a P3HT:PCBM blended layer. As a result, a higher reflectivity and a lower surface roughness of the metal cathodes gave a higher PCE. As shown in Fig. 7, surface roughness was shown to determine the surface energy of the $\mathrm{ZnO}$ layer and thus determine the D/A interfacial area in the active layer deposited on top. The efficiency of the device increases from $2.7 \%$ to $3.9 \%$ when the root-mean-square roughness of the $\mathrm{ZnO}$ layer decreases from 48 to $1.9 \mathrm{~nm} .{ }^{113}$ In addition, Heeger and colleagues report the controlled nano morphology of semiconducting polymers on chemically and mechanically stable nano grooves. ${ }^{114,115}$ Other studies used diamond scratches on $\mathrm{SiO}_{2}$ substrates to induce the alignment in slow, macroscopic limited solution casting. After alignment, the transport of the hole is enhanced by more than an order of magnitude. ${ }^{116,117}$ When the physical dimensions of the textured substrate are carefully chosen, it is indeed possible to achieve a conformal active layer on the light-harvested textured substrate for a more efficient OSC. The exact morphology of an active-layer on a grating is a strong function of the underlying topographical dimensions. $^{118}$

\subsection{Surface dynamics effect}

The pressure on the interface contact has an impact on the performance of OSCs. ${ }^{119}$ Pressure was applied to the model bilayer and OSC structure using a polydimethylsiloxane (PDMS) stamper. As compliant, semi-rigid and rigid particles interlock between adjacent layers of the model solar cell structure, an evolving surface contact profile occurs (in Fig. 8a-c). Applying pressure on the OSC layer again causes a change in the orientation of the polymer backbone in P3HT and PEDOT:PSS. The bonds between the chains are stretched, elongated and ordered, as shown in the out-of-plane and in-plane outlines of the GIWAXS (Fig. 8d-f). With the application of the pressure in

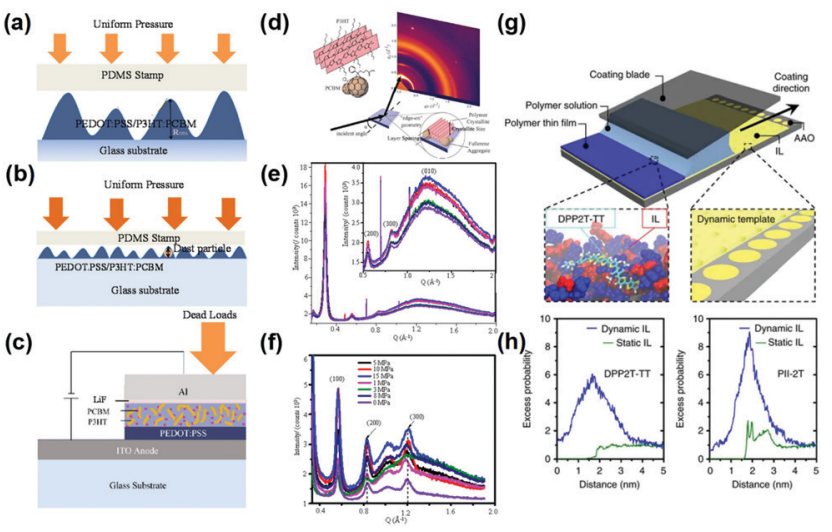

Fig. 8 Multilayered nanostructures adopted in the pressure-assisted organic photovoltaic cell fabrication under (a) rough surface contacts with blister height and (b) smooth surface contact with trapped particles, and (c) complete device showing multilayers with pressure applications. (d) The interaction between the grazing incidence $X$-ray beam and the polymer blend films that have been subjected to $10 \mathrm{MPa}$ pressure. 1D profile for the out-of-plane (e) and the in-plane (f) directions for P3HT and P3HT:PCBM films, respectively. Reproduced with permission. ${ }^{119}$ Copyright 2017, American Physical Society. (g) Schematic (not to scale) of meniscusguided coating on the IL [EMIM][TFSI] hosted in nanoporous anodized aluminum oxide dynamic template. The black arrow indicates the coating direction. In the inset, part of the IL wetting layer is artificially removed to reveal the nanocomposite structure underneath. (h) An excess probability distribution for dimeric DPP2T-TT and PII-2T in the presence of dynamic versus static ionic liquid surfaces. Reproduced with permission. ${ }^{22}$ Copyright 2017, Nature Publishing Group.

the out-of-plane direction and perpendicular to the substrate, the bond between the polymer main chains is also elongated in the in-plane direction, thereby forming an on-edge configuration. ${ }^{119}$ In addition, the capillary action in the confined mold plays a key role in the phase separation of the film and polymer crystallization. The nanoimprint process can improve the crystallinity and multi-dimensional chain arrangement of the polymer to achieve more effective charge transfer, and allow fine phase separation between the donors and acceptors, thereby promoting exciton dissociation and improving charge transfer excitons. ${ }^{120}$

In solution processing polymers, Diao et al. ${ }^{22}$ proposed the concept of dynamic templating to expedite polymer nucleation and the ensuing assembly process, and reveal that surface reconfigurability is a key to promoting template-polymer interactions improving the film morphology across length scales and enhancing the mobility of charge carriers as well as $\pi-\pi$ and polymer backbone directions, thereby lowering the polymer nucleation barrier. To address the mismatch between the time scale of polymer crystallization and the evaporation rate in the rapid solution casting process, they used ionic liquid ([EMIM] [TFSI]) hosted in nanoporous media (anodized aluminum oxide) as dynamic templates to enhance and direct conjugate polymer crystallization, since ionic liquid has ultrafast surface dynamics and strong ion- $\pi$ and $\pi-\pi$ electrostatic interactions with the donor and acceptor polymer backbones. As shown in Fig. 8g, using a dynamic template as a coating substrate, the highly consistent, highly crystalline polymer film 
gets a large area and charge transfer is enhanced several times. The synergy between dynamic-induced templated nucleation and unidirectional flow-guided crystal growth led to the formation of highly aligned, highly crystalline polymer thin films. Li et al., ${ }^{121}$ demonstrated that the morphological stability and lifetime of PCDTBT/PCBM solar cells under thermal stress are highly dependent on the substrate interface on which the active layer is deposited. They found that compared to conventional devices using PEDOT:PSS substrates, the stability of devices using $\mathrm{ZnO}$ substrates is greatly improved under moderate thermal stress. This improved stability was observed to be associated with PCBM nucleation at a $50 \mathrm{~nm}$ scale, which was strongly influenced by different substrate interfaces. Wang et al., ${ }^{122}$ found that using this $\pi$-assembly approach, a structural scaffold acts as an integral structural component of the assembled system, which enhanced performance over its individual components in donor-acceptor type (PDI-graphene/polythiophene) solar cells. Mauger et al., ${ }^{123}$ relate the relationship between metal material distribution and the chemistry at the $\mathrm{BHJ}$-metal interface to device performance and PCBM aggregate formation. A covering metal electrode has a profound effect on the vertical concentration profile. In particular, due to the interaction with the cover layer, the vertical concentration profile changes abruptly when the $\mathrm{BHJ}$ layer is gently heated. It is shown that surface energies and solvent additives greatly impact heat-induced vertical segregation.

\section{Interface morphology control in the $\mathrm{BHJ}$ active layer by different processing}

Generally speaking, the interaction between donors and acceptors in the $\mathrm{BHJ}$ active layer is also different, which will cause differences in surface energy. A large part of the work is to improve the morphology for the synthesis of new materials, such as the changes in the chain structure and the optimization of the alkyl side chain length and end groups. ${ }^{13,28,60}$ However, this article does not review the synthesis of new materials, but mainly describes the control methods in the deposition process.

\subsection{Solvent effect in the $\mathrm{BHJ}$ active layer}

In particular, the use of $\mathrm{BHJ}$ with a good composition gradient in the vertical direction to establish charge selectivity at the electrode has been proposed as an effective method to improve the efficiency of OSCs regardless of the type of donor and acceptor material. ${ }^{33,36,57,90,124,125}$ Specifically, donor preferential segregation to the anode active layer interface can block electrons and enhance hole collection, thereby improving short-circuit current density and device performance. In contrast, fullerene segregation at the interface between the anode and the active $\mathrm{BHJ}$ layer significantly increases the device series resistance, impedes hole delivery and extraction, and results in decreased device performance. ${ }^{125-127}$ The segregation of the electron acceptor phase can be controlled within the blend by surface energy controlled in the $\mathrm{BHJ}$ active layer.
As a general guideline, the solvent must be capable of dissolving all of the components in the blend film to a sufficient concentration to form a continuous film of the desired thickness and wetting the surface of the desired substrate. ${ }^{128-130}$ Coating from a single solvent solution produces a film having optoelectronic properties determined by solution parameters (e.g., relative solubility, boiling point, viscosity, etc.) and spin coating processes (e.g., concentration, mixing ratio, spin speed and time, etc.). ${ }^{34,70}$ At the same time, vapor pressure, surface tension and temperature also have a great influence on the morphology of the final film to the formation of the $\mathrm{BHJ}$ layer. Casting from a typically the $\mathrm{BHJ}$ layer results in a non-ideal morphology where the phase separation between the $\mathrm{BHJ}$ blend components is insufficient or excessive, and/or within the domain is orderly, thereby reducing device efficiency. In order to improve efficiency, the cosolvent (volume ratio of more than $10 \%$ ) has to also promote phase separation and organization of the $\mathrm{BHJ}$ component during evaporation, ${ }^{131-133}$ because the cast film prepared from different solvents has a large difference in surface morphology, indicating the important role of the solvent in controlling the morphology of the film. Cao et al., ${ }^{134}$ found that the pre-aggregation of PTzBI and N2200 polymers in 2-methyltetrahydrofuran (Me-THF) is the key factor to dramatically increase the device efficiency from $\approx 1 \%$ (treated by $\mathrm{CB}$ ) to $\approx 11 \%$ (treated by Me-THF). When CB is used as a solvent, both the donor and acceptor polymers dissolve well and most will disaggregate. In contrast, both donor and acceptor polymers exhibit strong aggregation in Me-THF. The donor and acceptor blend films exhibit pure domains with appropriate molecular packing structures. Moreover, they demonstrated that by using a green solvent system based on cyclopentyl methyl ether (CPME) to process the $\mathrm{BHJ}$ form, the performance of the all-polymer solar cells can be further improved to $11 \%$. $^{135}$

For certain polymer-fullerene combinations, studies have shown that the role of the co-solvent is to increase the domain size ${ }^{131}$ which is usually due to polymer aggregation in solution. As shown in Fig. 9, when casting a film with a single solvent, large $(>100 \mathrm{~nm})$ droplet-like fullerene enriched regions are formed in several polymer-fullerene blends. Studies have shown that these larger fullerene domains may be derived from $\mathrm{L}-\mathrm{L}$ phase separation during solvent evaporation. When the same blend is processed with a suitable co-solvent, large droplet-like areas are not found and a more compact form is formed, providing higher photovoltaic performance. A prominent example is highly efficient OSCs based on PTB7 and $\mathrm{PC}_{71} \mathrm{BM}$ in co-solvent with a certified efficiency of $9.2 \%$ using an inverted structure. ${ }^{130}$ Liu et al., ${ }^{136,137}$ studied the in situ drying of a blade-coated and drop-cast films in which a co-solvent decreases domain size. Janssen et al., ${ }^{130}$ investigated layer thickness, phase separation, and polymer aggregation during in situ evaporation of the solvent under actual process conditions. In a single solvent system, when the solid-liquid content is about $20 \%$ by volume, a large amount of the fullerene region is formed by liquid-liquid phase separation. Under such supersaturated conditions, the co-solvent will cause polymer aggregation with a solids content below 20 vol\% and prevent the formation of large domains. 

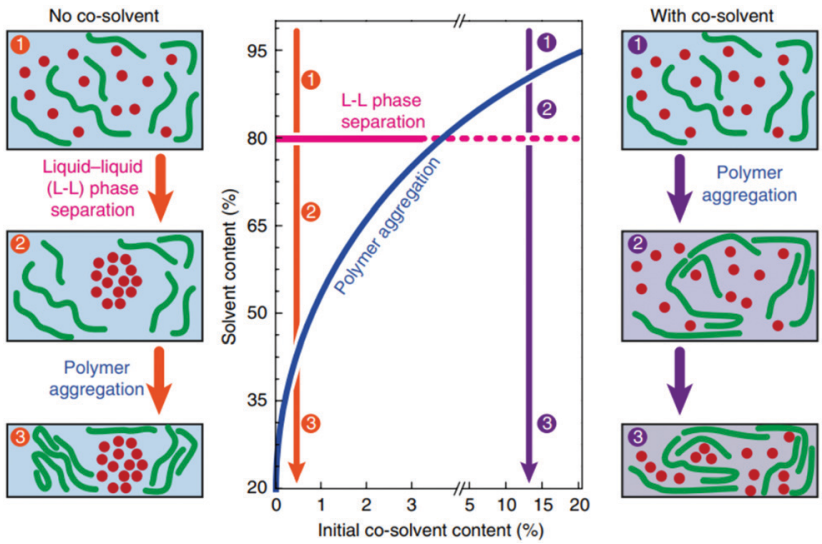

Fig. 9 Schematic phase diagram revealing the role of cosolvent in inducing polymer aggregation at higher solvent contents which, in turn, prevents large-scale liquid-liquid phase separation during drying and results in optimized morphologies. Reproduced with permission. ${ }^{130}$ Copyright 2015, Nature Publishing Group.

Small amounts of additional solvents or anti-solvent (less than $10 \%$ ) can also have a disproportionately large effect on the drying and film formation process. Solvent additives can affect the microstructure of $\mathrm{BHJ}$ by controlling the molecular order and orientation of the pure donor/acceptor domains and their degree of phase separation. Compared to co-solvent, an important advantage of solvent additives is their relative freedom of choice. ${ }^{70,138-140}$ It must have a minimum portion that is miscible with the deposition solvent, but can freely dissolve the donor, acceptor, both or neither. In a blend of p-DTS(FBTTh $\left.{ }_{2}\right)_{2}$ with $\mathrm{PC}_{71} \mathrm{BM}$ with $\mathrm{CB}$ solvent, the presence of the 1,8-diiodooctane (DIO) solvent additive can severely affect the morphology of the BHJ, thereby increasing the efficiency from $1.8 \%$ to $7.0 \% .{ }^{141}$ Peet et al.,${ }^{142}$ also found that higher photocurrents could be achieved in the P3HT:PCBM system when $n$-octylthiol (1-octanethiol) was used as a solvent additive, since the $n$-octylthiol can induce structural order in P3HT, increasing mobility in BHJ thin-film transistors. Unlike the case of P3HT: PCBM, an additive for alkyl dithiols mainly promotes phase separation and has little effect on the crystallinity of the donor. Lee et al. ${ }^{143}$ demonstrated that 1,8-octanedithiol (ODT) is purely a "processing additive", which does not react or dope the polymer in any way. ODT selectively dissolves $\mathrm{PC}_{71} \mathrm{BM}$ from the PCPDTBT:PC ${ }_{71} \mathrm{BM}$ BHJ films, then remains in the film after the deposition solvent evaporates due to its lower vapor pressure, which results in fullerene aggregates as the additive evaporates. ${ }^{55}$ As shown in Fig. 10, the AFM and TEM images show homogeneous nanostructures. The contrast of the PCPDTBT:PC ${ }_{71} \mathrm{BM}$ film without DIO treatment is weak, indicating that the donor and acceptor are highly intermixed on a molecular scale. In contrast, the treatment with additive DIO promoted phase separation, which revealed larger interconnected regions of PCPDTBT and $\mathrm{PC}_{71} \mathrm{BM}$ components. Experiments have shown that ODT and DIO are effective solvent additives for BHJ blends that do not sufficiently phase separate during deposition due to extended drying times and solvents that cause (a)
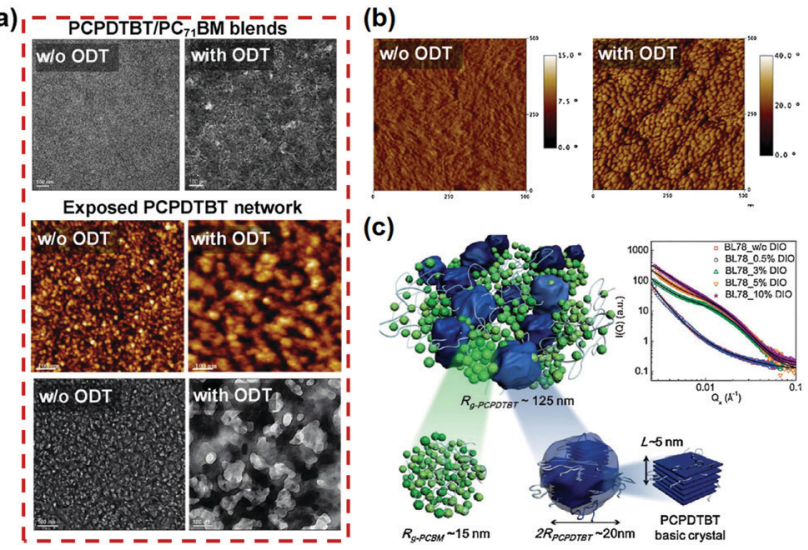

Fig. 10 Examples of promoting phase separation by processing with solvent additives. (a) Top: TEM images of PCPDTBT:PC ${ }_{71} B M$ BHJ blends. Bottom: AFM and TEM images of exposed PCPDTBT networks from PCPDTBT:PC ${ }_{71} B M$. (b) Phase images of PCPDTBT:PC $C_{71} B M$. (c) Illustration of the bi-hierarchical nanostructures of PCPDTBT:PC ${ }_{71} B M$. Inset: GISAXS profiles of PCPDTBT:PC ${ }_{71} B M$ BHJ processed with different amounts of additives. Reproduced with permission. ${ }^{55}$ Copyright 2013, Elsevier Ltd.

poor crystallinity of the donor. ${ }^{55,131,144} 1$-chloronaphthalene $(1 \mathrm{CN})$ creates a finer $\mathrm{BHJ}$ morphology by facilitating a tighter alignment of donors and acceptors, otherwise it is easier to separate quickly. With $2 \% \mathrm{v} / \mathrm{v} 1 \mathrm{CN}$, the domain size of the $\mathrm{BHJ}$ component was significantly reduced and the PCE increased from $1.6 \%$ to $4.9 \%{ }^{145} 1 \mathrm{CN}$ was chosen as a solvent additive because of its high boiling point and ability to dissolve the polymer to a greater extent than the deposition solvent CB. ${ }^{145,146}$ Diphenyl ether (DPE), as an aromatic solvent additive, also appears to increase the miscibility of donors and acceptors. In the DT-PDPP2T-TT:PC ${ }_{71}$ BM system, Choi et al. ${ }^{147}$ used DPE as a solvent additive to optimize the morphology of BHJ films to improve the PCE from $3.2 \%$ to a remarkable $9.5 \%$.

Adding a small amount of amorphous polymer polystyrene (PS) with the optimized molecular weight can increase the crystallinity of the photoactive phase and the redistribution of PCBM molecules away from the anode interface by interfacial tension to improve the overall photovoltaic efficiency of PCDTBT:PCBM inverted BHJ solar cells. ${ }^{148}$ Sun et al.,${ }^{149}$ have shown that adding a small amount (5 wt\%) of PS-b-P3HT copolymer as a solid additive in the P3HT:PCBM blend can reduce the interfacial tension between P3HT and PCBM and prevent PCBM from layering at the following locations. Graham et al., ${ }^{150}$ reported that polydimethylsiloxane (PDMS) increases the PCE of a blend of small molecules 1-EtHx and $\mathrm{PC}_{71} \mathrm{BM}$ based on different nucleation from $1.3 \%$ to $2.2 \%$ by nucleating a smaller donor domain, because PDMS more likely operates as a nucleation agent.

For fullerene and non-fullerene blends, solvent additives also have an effect on OSC performance. ${ }^{151,152}$ Due to the structural versatility of non-fullerene acceptors, the optimization of the morphologies of the active layers can be achieved using additional complicated treatments, such as binary additive processing and thermal annealing. For example, a binary additive consisting of ODT and DIO is used to optimize the 
device performance of FTAZ: ITIC-Th. $J_{\mathrm{sc}}$ and FF are strongly influenced by domain size and relative domain purity. ${ }^{153}$ Three analogues of ITIC, ITIC-F and ITIC-Th1 with different endcapping groups or side-chains were selected as non-fullerene acceptors for an alkylsilyl functionalized copolymer donor (PBDS-T). Huang et al. ${ }^{154}$ found the crystallinity of each component and the difference in the surface tensions greatly impact the morphology of blend films and device performance. From the perspective of non-fullerene structural variability, there are currently few guidelines for precisely controlling the morphology of polymer donor and fused ring acceptor blends. ${ }^{152}$ In particular, the research on the mechanism of morphology regulation needs to be further expanded.

\subsection{Post-treatment for the $\mathrm{BHJ}$ active layer in OSCs}

A variety of post-treatment methods can alter the surface energy of the polymer blend to affect the photovoltaic properties of the film. Annealing processes in OSCs can be divided into two categories: thermal annealing ${ }^{131,155-157}$ and solvent annealing. ${ }^{158-160}$ In P3HT:PCBM, thermal annealing exhibits a particularly effective post-treatment technique. The regioregular $\mathrm{P} 3 \mathrm{HT}$ is capable of forming highly crystalline domains, but the presence of PCBM kinetically hinders the ordering of the donor. ${ }^{155}$ It has been shown that the crystallinity of P3HT can be increased by thermal annealing to form crystallites having a conjugated chain ( $a$-axis orientation) parallel to the substrate. ${ }^{161}$ Thermal annealing of the film softens the P3HT polymer. After thermal annealing, P3HT was grown in all films to show the preferred orientation. This phenomenon can be explained by surface energy-driven "secondary grain growth", similar to inorganic semiconductors. ${ }^{162}$ As shown in Fig. 11, the concentration gradient varies from a PCBM-rich near the substrate side to a P3HT-rich concentration gradient near the free (air) surface. After various post-treatments (such as thermal annealing or vaporization annealing), the vertical composition profile also shows a similar concentration gradient, but with PCBM protrusions on the surface. Fig. 11e and f shows a typical PCBM distribution before and after vaporization or thermal annealing.

Solvent vapor annealing (SVA) is an extension of this technology by introducing a media container into a closed container so that it can be swollen with other media. Swelling the film with a solvent vapor can also be used to reverse vitrify the blend of polymer and fullerene to provide a more thermodynamically favorable morphology.

SVA was originally introduced as an alternative to thermal annealing because block polymer exhibits thermal degradation due to high molar mass, problematic heat-driven transitions or slow kinetic phenomena. The solvent annealing method controls the nanomorphology of the polymer by the speeding rate of the solvent removed. SVA has been shown to rapidly optimize blend organization due to increased chain mobility, possibly reduced interaction parameter $(\chi)$ (depending on solvent polarity) and adjustable surface energy. ${ }^{164}$ However, unlike thermal annealing, depending on the affinity of the solvent for the $\mathrm{BHJ}$ component and its vapor pressure, the choice of solvent vapor can direct the evolution of the phase to (a)

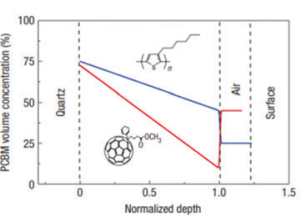

(c)

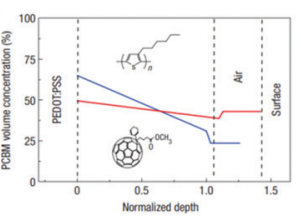

(e)

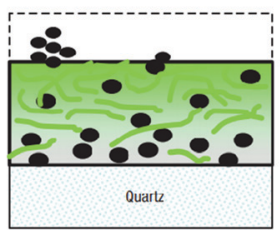

(b)

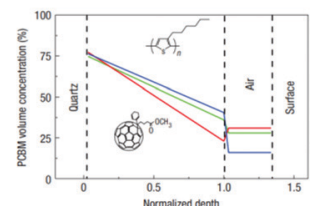

(d)

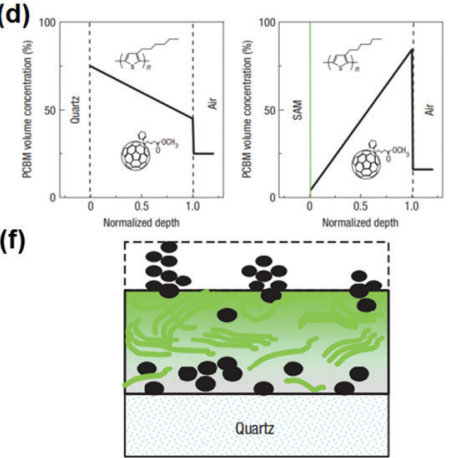

Fig. 11 Vertical composition profiles in P3HT:PCBM films as deduced using ellipsometry. $(a-d)$ PCBM concentration curve obtained by analysis of ellipsometric data of the P3HT:PCBM blend film: (a) spin coating on fused silica before (blue) and after (red) thermal annealing; (b) spin-coated on fused silica at different rpm; (c) spin-coated on PEDOT:PSS coated fused silica before (blue) and (red) vapor annealing; (d) spin-coated on a monolayer pre-coated with hydrophobic SAMs silica (left) and Si wafer. (e and f) A schematic of a model used to fit ellipsometric data, showing a typical PCBM distribution before (e) and after ( $f$ ) vaporization or thermal annealing. Reproduced with permission. ${ }^{163}$ Copyright 2008, Nature Publishing Group.

a greater or finer direction. Kelly et al., ${ }^{165}$ utilized a variable pressure solvent vapor annealing (VP-SVA) system for reproducibly and tunably annealing the active layer to produce a highly controllable film morphology. It was also found that VP-SVA is not only useful for the well-studied P3HT:PCBM model system, but also for the active layer based on non-fullerene acceptors. Especially in BHJ solar cells with non-fullerene acceptors, the effectiveness of SVA is superior to thermal annealing. SVA treatment showed a more balanced hole and electron mobility, which significantly inhibited trap-assisted recombination. ${ }^{166}$ Russell et al. ${ }^{167}$ also found that using a suitable SVA, especially with thermal annealing and SVA, can significantly improve the performance of devices based on the shortest oligomer BIT4F. Both thermal annealing and solvent vapor annealing drive the system to the most thermodynamically stable state, although this may not be the best state for device performance. The morphology obtained by post-treatment may also be limited by the nanostructure of the initial film formed during solution casting. It is noted that the deposition solvent has a strong influence morphology, but the choice of deposition solvent is strongly limited by the solubility of the donor and acceptor components. The solubility parameter of the polar solvent has been shown to correlate with changes in surface roughness when the active layer is directly exposed to the solvent. ${ }^{168}$ Zheng et al., ${ }^{169}$ studied the effect of different polar solvents on the photovoltaic performance of $\mathrm{PTB} 7: \mathrm{PC}_{71} \mathrm{BM}$ by applying different polar solvents (including methanol, ethanol, dimethyl sulfoxide, acetone and isopropanol) SVA. They found that both 
the solubility parameters and viscosity of the solvent are critical to the SVA performance. Compared to the other four solvents, methanol with high solubility parameters and low viscosity can significantly increase the PCE of the device from $6.55 \%$ to $8.13 \%$.

\section{Summary and outlook}

Due to weak van der Waals interactions between molecules, organic semiconductors are prone to structural modification. The design principle derived from a basic understanding of the relationship between molecular structures, processing conditions, BHJ morphology and device function can provide higher OSC efficiency. In particular, controlling the BHJ morphology of donor and acceptor materials is the key to achieving high device reproducibility. Surface energy control provides tools for tailoring the active layer self-assembly and phase separation kinetics during deposition, which includes substrate surface energy controlled and surface energy controlled in the $\mathrm{BHJ}$ active layer. In the case of the $\mathrm{BHJ}$ device, surface energy can play an important role in the morphology by directing phase separation during film deposition, drying and annealing. Surface energy naturally changes with interface modification. Organic molecular packaging and polymorphism are controlled by substrate interactions. In particular, substrate-directed film morphology can affect charge transfer performance. This is because the charge extraction process is improved when the donor polymer domain segregates toward the anode interface and the acceptor fullerene domain segregates toward the cathode interface. Vertical phase separation may result in efficient extraction of charge at the electrode/ blend interface. Surface energy, surface morphology and surface dynamics are important influences in establishing design rules and understanding the critical role of substrates in determining the morphology of solvent-based films. The degree of vertical phase segregation depends on the nature of the substrate and the deposition treatment conditions, and can also be controlled by changing the surface energy of the substrate to change the blend-substrate interface.

To consider the characteristics of the organic semiconductor, the geometry of the $\mathrm{BHJ}$ morphology must be finely tuned. In the co-solvent system, solvent additives have provided tools for manipulating phase separation of the active layer during deposition, where donor crystallization is initiated by using a slow-drying poor solvent as an additive. Both thermal annealing and solvent vapor annealing drive the system to the most thermodynamically stable state, which may result in a relatively optimal arrangement of photovoltaic performance. Indeed, understanding the effects of solvent additives and posttreatment on film formation has enabled them to be applied and combined effectively and synergistically to improve OSC performance. Optimal solar cell performance can be achieved by balancing the ordered and pure domains of each component with the interfacial mixed-phase to promote exciton dissociation into free charges. By improving the surface energy in the
$\mathrm{BHJ}$ system, the three-phase morphology constitutes our understanding of the most ideal BHJ structure.

Utilizing the difference in surface energy, a finer assembly morphology of the $\mathrm{BHJ}$ active layer can be obtained. Among them, surface energy, viscosity, diffusion and evaporation rate, and geometric factors play an important role. A more basic understanding of the interactions between these parameters associated with organic semiconductors is necessary to advance such promising manufacturing methods. Ongoing challenges include a better understanding of the interface microdomain control and charge transport mechanism of semiconductor polymers. Therefore, new surface characterization methods are needed to more intuitively observe the morphological changes of the interface microdomains during the deposition process.

\section{Conflicts of interest}

There are no conflicts to declare.

\section{Acknowledgements}

This work was financially supported by the National Key Research and Development Program of China (2017YFA0206600), the National Natural Science Foundation of China (No. 21922505 and 21674006) and the Strategic Priority Research Program of Chinese Academy of Sciences (No. XDB36000000). Y. Zhang acknowledges the financial support from the National Natural Science Foundation of China (No. 21875012 and 21674006).

\section{References}

1 C. J. Brabec, A. Cravino, D. Meissner, N. S. Sariciftci, T. Fromherz, M. T. Rispens, L. Sanchez and J. C. Hummelen, Origin of the open circuit voltage of plastic solar cells, Adv. Funct. Mater., 2001, 11, 374-380.

2 C. J. Brabec, N. S. Sariciftci and J. C. Hummelen, Plastic solar cells, Adv. Funct. Mater., 2001, 11, 15-26.

3 R. Sondergaard, M. Hosel, D. Angmo, T. T. Larsen-Olsen and F. C. Krebs, Roll-to-roll fabrication of polymer solar cells, Mater. Today, 2012, 15, 36-49.

4 M. C. Scharber and N. S. Sariciftci, Efficiency of bulkheterojunction organic solar cells, Prog. Polym. Sci., 2013, 38, 1929-1940.

5 S. E. Shaheen, C. J. Brabec, N. S. Sariciftci, F. Padinger, T. Fromherz and J. C. Hummelen, $2.5 \%$ efficient organic plastic solar cells, Appl. Phys. Lett., 2001, 78, 841-843.

6 Y. B. Lin, B. Adilbekova, Y. Firdaus, E. Yengel, H. Faber, M. Sajjad, X. P. Zheng, E. Yarali, A. Seitkhan, O. M. Bakr, A. El-Labban, U. Schwingenschlogl, V. Tung, I. McCulloch, F. Laquai and T. D. Anthopoulos, 17\% Efficient Organic Solar Cells Based on Liquid Exfoliated WS2 as a Replacement for PEDOT:PSS, Adv. Mater., 2019, 31, 1902965.

7 L. X. Meng, Y. M. Zhang, X. J. Wan, C. X. Li, X. Zhang, Y. B. Wang, X. Ke, Z. Xiao, L. M. Ding, R. X. Xia, H. L. Yip, Y. Cao and Y. S. Chen, Organic and solution-processed 
tandem solar cells with $17.3 \%$ efficiency, Science, 2018, 361, 1094-1098.

8 B. B. Fan, D. F. Zhang, M. J. Li, W. K. Zhong, Z. M. Y. Zeng, L. Ying, F. Huang and Y. Cao, Achieving over 16\% efficiency for single-junction organic solar cells, Sci. China: Chem., 2019, 62, 746-752.

9 X. W. Zhan, A. Facchetti, S. Barlow, T. J. Marks, M. A. Ratner, M. R. Wasielewski and S. R. Marder, Rylene and Related Diimides for Organic Electronics, Adv. Mater., 2011, 23, 268-284.

10 W. C. Zhao, D. P. Qian, S. Q. Zhang, S. S. Li, O. Inganas, F. Gao and J. H. Hou, Fullerene-Free Polymer Solar Cells with over 11\% Efficiency and Excellent Thermal Stability, Adv. Mater., 2016, 28, 4734-4739.

11 Z. C. Zhou, S. J. Xu, J. N. Song, Y. Z. Jin, Q. H. Yue, Y. H. Qian, F. Liu, F. L. Zhang and X. Z. Zhu, Highefficiency small-molecule ternary solar cells with a hierarchical morphology enabled by synergizing fullerene and non-fullerene acceptors, Nat. Energy, 2018, 3, 952-959.

12 L. L. Zhan, S. X. Li, T. K. Lau, Y. Cui, X. H. Lu, M. M. Shi, C. Z. Li, H. Y. Li, J. H. Hou and H. Z. Chen, Over $17 \%$ efficiency ternary organic solar cells enabled by two nonfullerene acceptors working in an alloy-like model, Energy Environ. Sci., 2020, 13, 635-645.

13 Q. S. Liu, Y. F. Jiang, K. Jin, J. Q. Qin, J. G. Xu, W. T. Li, J. Xiong, J. F. Liu, Z. Xiao, K. Sun, S. F. Yang, X. T. Zhang and L. M. Ding, 18\% Efficiency organic solar cells, Sci. Bull., 2020, 65, 272-275.

14 R. Abbel, Y. Galagan and P. Groen, Roll-to-Roll Fabrication of Solution Processed Electronics, Adv. Eng. Mater., 2018, 20, 1701190.

15 X. D. Gu, Y. Zhou, K. Gu, T. Kurosawa, Y. K. Guo, Y. K. Li, H. R. Lin, B. C. Schroeder, H. P. Yan, F. Molina-Lopez, C. J. Tassone, C. Wang, S. C. B. Mannsfeld, H. Yan, D. H. Zhao, M. F. Toney and Z. N. Bao, Roll-to-Roll Printed Large-Area All-Polymer Solar Cells with 5\% Efficiency Based on a Low Crystallinity Conjugated Polymer Blend, Adv. Energy Mater., 2017, 7, 1602742.

16 F. C. Krebs, Roll-to-roll fabrication of monolithic large-area polymer solar cells free from indium-tin-oxide, Sol. Energy Mater. Sol. Cells, 2009, 93, 1636-1641.

17 S. S. Babu, H. Mohwald and T. Nakanishi, Recent progress in morphology control of supramolecular fullerene assemblies and its applications, Chem. Soc. Rev., 2010, 39, 4021-4035.

18 Y. Diao, L. Shaw, Z. A. Bao and S. C. B. Mannsfeld, Morphology control strategies for solution-processed organic semiconductor thin films, Energy Environ. Sci., 2014, 7, 2145-2159.

19 J. A. Reinspach, Y. Diao, G. Giri, T. Sachse, K. England, Y. Zhou, C. Tassone, B. J. Worfolk, M. Presselt, M. F. Toney, S. Mannsfeld and Z. N. Bao, Tuning the Morphology of Solution-Sheared P3HT:PCBM Films, ACS Appl. Mater. Interfaces, 2016, 8, 1742-1751.

20 Y. Diao, B. C. K. Tee, G. Giri, J. Xu, D. H. Kim, H. A. Becerril, R. M. Stoltenberg, T. H. Lee, G. Xue, S. C. B. Mannsfeld and Z. N. Bao, Solution coating of large-area organic semiconductor thin films with aligned single-crystalline domains, Nat. Mater., 2013, 12, 665-671.

21 Y. Diao, Y. Zhou, T. Kurosawa, L. Shaw, C. Wang, S. Park, Y. K. Guo, J. A. Reinspach, K. Gu, X. D. Gu, B. C. K. Tee, C. H. Pang, H. P. Yan, D. H. Zhao, M. F. Toney, S. C. B. Mannsfeld and Z. A. Bao, Flow-enhanced solution printing of allpolymer solar cells, Nat. Commun., 2015, 6, 7955.

22 E. Mohammadi, C. K. Zhao, Y. F. Meng, G. Qu, F. J. Zhang, X. K. Zhao, J. G. Mei, J. M. Zuo, D. Shukla and Y. Diao, Dynamic-template-directed multiscale assembly for largearea coating of highly-aligned conjugated polymer thin films, Nat. Commun., 2017, 8, 16070.

23 G. Giri, E. Verploegen, S. C. B. Mannsfeld, S. AtahanEvernk, A. Aspuru-Guzik, M. F. Toney and Z. N. Bao, Tuning charge transport in solution sheared organic semiconductors using lattice strain, Nature, 2012, 480, 504-508.

24 R. Sun, J. Guo, C. Sun, T. Wang, Z. Luo, Z. Zhang, X. Jiao, W. Tang, C. Yang, Y. Li and J. Min, A universal layerby-layer solution-processing approach for efficient nonfullerene organic solar cells, Energy Environ. Sci., 2019, 12, 384-395.

25 S. Mukherjee, X. C. Jiao and H. Ade, Charge Creation and Recombination in Multi-Length Scale Polymer:Fullerene BHJ Solar Cell Morphologies, Adv. Energy Mater., 2016, 6, 1600699.

26 L. Zhang and W. Ma, Morphology optimization in ternary organic solar cells, Chin. J. Polym. Sci., 2017, 35, 184-197.

27 J. G. Liu, J. Han, Q. J. Liang, J. M. Xin, Y. B. Tang, W. Ma, X. H. Yu and Y. C. Han, Balancing Crystal Size in SmallMolecule Nonfullerene Solar Cells through Fine-Tuning the Film-Forming Kinetics to Fabricate Interpenetrating Network, ACS Omega, 2018, 3, 7603-7612.

28 T. Liu, L. J. Huo, S. Chandrabose, K. Chen, G. C. Han, F. Qi, X. Y. Meng, D. J. Xie, W. Ma, Y. P. Yi, J. M. Hodgkiss, F. Liu, J. Wang, C. L. Yang and Y. M. Sun, Optimized Fibril Network Morphology by Precise Side-Chain Engineering to Achieve High-Performance Bulk-Heterojunction Organic Solar Cells, Adv. Mater., 2018, 30, 1707353.

29 L. Ye, B. A. Collins, X. C. Jiao, J. B. Zhao, H. Yan and H. Ade, Miscibility-Function Relations in Organic Solar Cells: Significance of Optimal Miscibility in Relation to Percolation, Adv. Energy Mater., 2018, 8, 1703058.

30 N. D. Treat, A. Varotto, C. J. Takacs, N. Batara, M. AlHashimi, M. J. Heeney, A. J. Heeger, F. Wudl, C. J. Hawker and M. L. Chabinyc, Polymer-Fullerene Miscibility: A Metric for Screening New Materials for HighPerformance Organic Solar Cells, J. Am. Chem. Soc., 2012, 134, 15869-15879.

31 N. D. Treat and M. L. Chabinyc, Phase Separation in Bulk Heterojunctions of Semiconducting Polymers and Fullerenes for Photovoltaics, Annu. Rev. Phys. Chem., 2014, Vol. 65(65), 59-81.

32 C. Lee, Y. Li, W. Lee, Y. Lee, J. Choi, T. Kim, C. Wang, E. D. Gomez, H. Y. Woo and B. J. Kim, Correlation between Phase-Separated Domain Sizes of Active Layer 
and Photovoltaic Performances in All-Polymer Solar Cells, Macromolecules, 2016, 49, 5051-5058.

33 M. Kim, J. Lee, S. B. Jo, D. H. Sin, H. Ko, H. Lee, S. G. Lee and K. Cho, Critical factors governing vertical phase separation in polymer-PCBM blend films for organic solar cells, J. Mater. Chem. A, 2016, 4, 15522-15535.

34 L. M. Chen, Z. R. Hong, G. Li and Y. Yang, Recent Progress in Polymer Solar Cells: Manipulation of Polymer: Fullerene Morphology and the Formation of Efficient Inverted Polymer Solar Cells, Adv. Mater., 2009, 21, 1434-1449.

35 F. Liu, Y. Gu, X. B. Shen, S. Ferdous, H. W. Wang and T. P. Russell, Characterization of the morphology of solution-processed bulk heterojunction organic photovoltaics, Prog. Polym. Sci., 2013, 38, 1990-2052.

36 Y. J. Zhang, D. Deng, Z. Y. Wang, Y. H. Wang, J. Q. Zhang, J. Fang, Y. Yang, G. H. Lu, W. Ma and Z. X. Wei, Enhancing the Photovoltaic Performance via Vertical Phase Distribution Optimization in Small Molecule: PC71BM Blends, Adv. Energy Mater., 2017, 7, 1701548.

37 N. S. Gobalasingham, S. Noh, J. B. Howard and B. C. Thompson, Influence of Surface Energy on Organic Alloy Formation in Ternary Blend Solar Cells Based on Two Donor Polymers, ACS Appl. Mater. Interfaces, 2016, 8, 27931-27941.

38 Y. F. Liu, D. D. Tang, K. C. Zhang, P. Huang, Z. W. Wang, K. Zhu, Z. D. Li, L. G. Yuan, J. A. Fan, Y. Zhou and B. Song, Tuning Surface Energy of Conjugated Polymers via Fluorine Substitution of Side Alkyl Chains: Influence on Phase Separation of Thin Films and Performance of Polymer Solar Cells, ACS Omega, 2017, 2, 2489-2498.

39 H. W. Hsu, W. C. Chang, S. H. Tung and C. L. Liu, Surface Energy-Mediated Self-Patterning for High Performance Spray-Deposited Organic Field Effect Transistors, Adv. Mater. Interfaces, 2016, 3, 1500714.

40 S. Y. Kwak, C. G. Choi and B. S. Bae, Effect of Surface Energy on Pentacene Growth and Characteristics of Organic Thin-Film Transistors, Electrochem. Solid-State Lett., 2009, 12, G37-G39.

41 F. J. Zhang, E. Mohammadi, X. Y. Luo, J. Strzalka, J. G. Mei and Y. Diao, Critical Role of Surface Energy in Guiding Crystallization of Solution Coated Conjugated Polymer Thin Films, Langmuir, 2018, 34, 1109-1122.

42 J. Lal, S. Malkova, M. K. Mukhopadhyay, S. Narayanan, A. Fluerasu, S. B. Darling, L. B. Lurio and M. Sutton, Dewetting in immiscible polymer bilayer films, Phys. Rev. Mater., 2017, 1, 015601.

43 G. Reiter and G. R. Strobl, Progress in understanding of polymer crystallization, Springer, Berlin, New York, 2007.

44 H. Zhang, W. Y. Tan, S. Fladischer, L. L. Ke, T. Ameri, N. Li, M. Turbiez, E. Spiecker, X. H. Zhu, Y. Cao and C. J. Brabec, Roll to roll compatible fabrication of inverted organic solar cells with a self-organized charge selective cathode interfacial layer, J. Mater. Chem. A, 2016, 4, 5032-5038.

45 D. S. Germack, C. K. Chan, R. J. Kline, D. A. Fischer, D. J. Gundlach, M. F. Toney, L. J. Richter and D. M. DeLongchamp, Interfacial Segregation in Polymer/Fullerene
Blend Films for Photovoltaic Devices, Macromolecules, 2010, 43, 3828-3836.

46 G. L. Schulz and S. Ludwigs, Controlled Crystallization of Conjugated Polymer Films from Solution and Solvent Vapor for Polymer Electronics, Adv. Funct. Mater., 2017, 27, 1603083.

47 X. Y. Ding, J. H. Liu and T. A. L. Harris, A Review of the Operating Limits in Slot Die Coating Processes, AIChE J., 2016, 62, 2508-2524.

48 B. B. Patel and Y. Diao, Multiscale assembly of solutionprocessed organic electronics: the critical roles of confinement, fluid flow, and interfaces, Nanotechnology, 2018, 29, 044004.

49 V. Podzorov, Conjugated polymers long and winding polymeric roads, Nat. Mater., 2013, 12, 947-948.

50 M. Fahlman, S. Fabiano, V. Gueskine, D. Simon, M. Berggren and X. Crispin, Interfaces in organic electronics, Nat. Rev. Mater., 2019, 4, 627-650.

51 C. R. McNeill, Morphology of all-polymer solar cells, Energy Environ. Sci., 2012, 5, 5653-5667.

52 F. W. Zhao, C. R. Wang and X. W. Zhan, Morphology Control in Organic Solar Cells, Adv. Energy Mater., 2018, 8, 1703147.

53 R. Singh, J. Lee, M. Kim, P. E. Keivanidis and K. Cho, Control of the molecular geometry and nanoscale morphology in perylene diimide based bulk heterojunctions enables an efficient non-fullerene organic solar cell, J. Mater. Chem. A, 2017, 5, 210-220.

54 S. S. Nair and D. Kumar, Ternary Solvent System to Control the Morphology of Active Blend in Inverted Organic Solar Cells, Polym.-Plast. Technol. Eng., 2017, 56, 974-982.

55 H. C. Liao, C. C. Ho, C. Y. Chang, M. H. Jao, S. B. Darling and W. F. Su, Additives for morphology control in highefficiency organic solar cells, Mater. Today, 2013, 16, 326-336.

56 N. Li, J. D. Perea, T. Kassar, M. Richter, T. Heumueller, G. J. Matt, Y. Hou, N. S. Gueldal, H. W. Chen, S. Chen, S. Langner, M. Berlinghof, T. Unruh and C. J. Brabec, Abnormal strong burn-in degradation of highly efficient polymer solar cells caused by spinodal donor-acceptor demixing, Nat. Commun., 2017, 8, 14541.

57 L. F. Zhang, N. Yi, W. H. Zhou, Z. Yu, F. Liu and Y. W. Chen, Miscibility Tuning for Optimizing Phase Separation and Vertical Distribution toward Highly Efficient Organic Solar Cells, Adv. Sci., 2019, 6, 1900565.

58 Y. W. Tian, K. J. Qian, E. Jacobs, E. Amstad, D. S. Jones, L. Stella and G. P. Andrews, The Investigation of FloryHuggins Interaction Parameters for Amorphous Solid Dispersion Across the Entire Temperature and Composition Range, Pharmaceutics, 2019, 11, 420.

59 C. Q. Yan, S. Barlow, Z. H. Wang, H. Yan, A. K. Y. Jen, S. R. Marder and X. W. Zhan, Non-fullerene acceptors for organic solar cells, Nat. Rev. Mater., 2018, 3, 18003.

60 J. H. Hou, O. Inganas, R. H. Friend and F. Gao, Organic solar cells based on non-fullerene acceptors, Nat. Mater., 2018, 17, 119-128. 
61 L. R. Wu, L. C. Xie, H. M. Tian, R. X. Peng, J. M. Huang, B. Fanady, W. Song, S. T. Tan, W. G. Bi and Z. Y. Ge, Efficient ternary organic solar cells based on a twin spirotype non-fullerene acceptor, Sci. Bull., 2019, 64, 1087-1094.

62 J. Q. Zhang, H. S. Tan, X. G. Guo, A. Facchetti and H. Yan, Material insights and challenges for non-fullerene organic solar cells based on small molecular acceptors, Nat. Energy, 2018, 3, 720-731.

63 T. Liu, D. Meng, Y. H. Cai, X. B. Sun, Y. Li, L. J. Huo, F. Liu, Z. H. Wang, T. P. Russell and Y. M. Sun, High-Performance Non-Fullerene Organic Solar Cells Based on a SeleniumContaining Polymer Donor and a Twisted Perylene Bisimide Acceptor, Adv. Sci., 2016, 3, 1600117.

64 W. C. Zhao, S. S. Li, H. F. Yao, S. Q. Zhang, Y. Zhang, B. Yang and J. H. Hou, Molecular Optimization Enables over 13\% Efficiency in Organic Solar Cells, J. Am. Chem. Soc., 2017, 139, 7148-7151.

65 G. Y. Zhang, J. B. Zhao, P. C. Y. Chow, K. Jiang, J. Q. Zhang, Z. L. Zhu, J. Zhang, F. Huang and H. Yan, Nonfullerene Acceptor Molecules for Bulk Heterojunction Organic Solar Cells, Chem. Rev., 2018, 118, 3447-3507.

66 N. Yi, Q. Ai, W. Zhou, L. Huang, L. Zhang, Z. Xing, X. Li, J. Zeng and Y. Chen, Miscibility Matching and Bimolecular Crystallization Affording High-Performance Ternary Nonfullerene Solar Cells, Chem. Mater., 2019, 31, 10211-10224.

67 J. H. Gao, W. Gao, X. L. Ma, Z. H. Hu, C. Y. Xu, X. L. Wang, Q. S. An, C. L. Yang, X. L. Zhang and F. J. Zhang, Over $14.5 \%$ efficiency and $71.6 \%$ fill factor of ternary organic solar cells with $300 \mathrm{~nm}$ thick active layers, Energy Environ. Sci., 2020, 13, 958-967.

68 T. Liu, X. N. Xue, L. J. Huo, X. B. Sun, Q. S. An, F. J. Zhang, T. P. Russell, F. Liu and Y. M. Sun, Highly Efficient ParallelLike Ternary Organic Solar Cells, Chem. Mater., 2017, 29, 2914-2920.

69 Q. S. An, F. J. Zhang, J. Zhang, W. H. Tang, Z. B. Deng and B. Hu, Versatile ternary organic solar cells: a critical review, Energy Environ. Sci., 2016, 9, 281-322.

70 C. McDowell, M. Abdelsamie, M. F. Toney and G. C. Bazan, Solvent Additives: Key Morphology-Directing Agents for Solution-Processed Organic Solar Cells, Adv. Mater., 2018, 30, 1707114.

71 K. C. Gu and Y. L. Loo, The Polymer Physics of Multiscale Charge Transport in Conjugated Systems, J. Polym. Sci., Part B: Polym. Phys., 2019, 57, 1559-1571.

72 X. D. Gu, L. Shaw, K. Gu, M. F. Toney and Z. N. Bao, The meniscus-guided deposition of semiconducting polymers, Nat. Commun., 2018, 9, 534.

73 S. R. Scully and M. D. McGehee, Effects of optical interference and energy transfer on exciton diffusion length measurements in organic semiconductors, J. Appl. Phys., 2006, 100, 034907.

74 R. Rieger, D. Beckmann, A. Mavrinskiy, M. Kastler and K. Mullen, Backbone Curvature in Polythiophenes, Chem. Mater., 2010, 22, 5314-5318.

75 S. Fratini, M. Nikolka, A. Salleo, G. Schweicher and H. Sirringhaus, Charge transport in high-mobility conjugated polymers and molecular semiconductors, Nat. Mater., 2020, 19, 491-502.

76 A. Salleo, Charge transport in polymeric transistors, Mater. Today, 2007, 10, 38-45.

77 M. Ghasemi, H. W. Hu, Z. X. Peng, J. J. Rech, I. Angunawela, J. H. Carpenter, S. J. Stuard, A. Wadsworth, I. McCulloch, W. You and H. Ade, Delineation of Thermodynamic and Kinetic Factors that Control Stability in Non-fullerene Organic Solar Cells, Joule, 2019, 3, 1328-1348.

78 M. A. Alam, B. Ray, M. R. Khan and S. Dongaonkar, The essence and efficiency limits of bulk-heterostructure organic solar cells: A polymer-to-panel perspective, J. Mater. Res., 2013, 28, 541-557.

79 A. Pierre, M. Sadeghi, M. M. Payne, A. Facchetti, J. E. Anthony and A. C. Arias, All-Printed Flexible Organic Transistors Enabled by Surface Tension-Guided Blade Coating, Adv. Mater., 2014, 26, 5722-5727.

80 X. Y. Liu, C. Liu, K. Sakamoto, T. Yasuda, P. Xiong, L. J. Liang, T. Z. Yang, M. Kanehara, J. Takeya and T. Minari, Homogeneous dewetting on large-scale microdroplet arrays for solution-processed electronics, NPG Asia Mater., 2017, 9, e409.

81 K. C. Kwon, W. J. Dong, G. H. Jung, J. Ham, J. L. Lee and S. Y. Kim, Extension of stability in organic photovoltaic cells using UV/ozone-treated graphene sheets, Sol. Energy Mater. Sol. Cells, 2013, 109, 148-154.

82 T.-H. Lai, S.-W. Tsang, J. R. Manders, S. Chen and F. So, Properties of interlayer for organic photovoltaics, Mater. Today, 2013, 16, 424-432.

83 J. McGinty; N. Yazdanpanah; C. Price; J. H. ter Horst and J. Sefcik, Nucleation and Crystal Growth in Continuous Crystallization, The Handbook of Continuous Crystallization, The Royal Society of Chemistry, 2020, ch. 1, pp. 1-50.

84 L. Granasy, G. Tegze, G. I. Toth and T. Pusztai, Phase-field crystal modelling of crystal nucleation, heteroepitaxy and patterning, Philos. Mag., 2011, 91, 123-149.

85 E. Piorkowska and G. C. Rutledge, Handbook of polymer crystallization, 2013, DOI: 10.1002/9781118541838.

86 D. H. Kim, Y. D. Park, Y. S. Jang, H. C. Yang, Y. H. Kim, J. I. Han, D. G. Moon, S. J. Park, T. Y. Chang, C. W. Chang, M. K. Joo, C. Y. Ryu and K. W. Cho, Enhancement of fieldeffect mobility due to surface-mediated molecular ordering in regioregular polythiophene thin film transistors, $A d v$. Funct. Mater., 2005, 15, 77-82.

87 G. Reiter, Some unique features of polymer crystallisation, Chem. Soc. Rev., 2014, 43, 2055-2065.

88 J. H. Liu, I. A. Mikhaylov, J. H. Zou, I. Osaka, A. E. Masunov, R. D. McCullough and L. Zhai, Insight into how molecular structures of thiophene-based conjugated polymers affect crystallization behaviors, Polymer, 2011, 52, 2302-2309.

89 J. I. Lauritzen and J. D. Hoffman, Theory of Formation of Polymer Crystals with Folded Chains in Dilute Solution, J. Res. Natl. Bur. Stand., Sect. A, 1960, 64, 73-102.

90 L. Q. Huang, G. Wang, W. H. Zhou, B. Y. Fu, X. F. Cheng, L. F. Zhang, Z. B. Yuan, S. X. Xiong, L. Zhang, Y. P. Xie, A. D. Zhang, Y. D. Zhang, W. Ma, W. W. Li, Y. H. Zhou, 
E. Reichmanis and Y. W. Chen, Vertical Stratification Engineering for Organic Bulk-Heterojunction Devices, ACS Nano, 2018, 12, 4440-4452.

91 H. Zhang, R. C. Shallcross, N. Li, T. Stubhan, Y. Hou, W. Chen, T. Ameri, M. Turbiez, N. R. Armstrong and C. J. Brabec, Overcoming Electrode-Induced Losses in Organic Solar Cells by Tailoring a Quasi-Ohmic Contact to Fullerenes via Solution-Processed Alkali Hydroxide Layers, Adv. Energy Mater., 2016, 6, 1502195.

92 H. Zhang, T. Stubhan, N. Li, M. Turbiez, G. J. Matt, T. Ameri and C. J. Brabec, A solution-processed barium hydroxide modified aluminum doped zinc oxide layer for highly efficient inverted organic solar cells, J. Mater. Chem. A, 2014, 2, 18917-18923.

93 B. Meng, Z. Y. Wang, W. Ma, Z. Y. Xie, J. Liu and L. X. Wang, A Cross-Linkable Donor Polymer as the Underlying Layer to Tune the Active Layer Morphology of Polymer Solar Cells, Adv. Funct. Mater., 2016, 26, 226-232.

94 Z. Zheng, S. Q. Zhang, J. Q. Wang, J. Q. Zhang, D. Y. Zhang, Y. Zhang, Z. X. Wei, Z. Y. Tang, J. H. Hou and H. Q. Zhou, Exquisite modulation of $\mathrm{ZnO}$ nanoparticle electron transporting layer for high-performance fullerene-free organic solar cell with inverted structure, J. Mater. Chem. A, 2019, 7, 3570-3576.

95 H. Kang, S. Kee, K. Yu, J. Lee, G. Kim, J. Kim, J. R. Kim, J. Kong and K. Lee, Simplified Tandem Polymer Solar Cells with an Ideal Self-Organized Recombination Layer, Adv. Mater., 2015, 27, 1408-1413.

96 S. Q. Bi, X. Y. Leng, Y. X. Li, Z. Zheng, X. N. Zhang, Y. Zhang and H. Q. Zhou, Interfacial Modification in Organic and Perovskite Solar Cells, Adv. Mater., 2019, 31, 1805708.

97 Z. Zheng, Q. Hu, S. Q. Zhang, D. Y. Zhang, J. Q. Wang, S. K. Xie, R. Wang, Y. P. Qin, W. N. Li, L. Hong, N. N. Liang, F. Liu, Y. Zhang, Z. X. Wei, Z. Y. Tang, T. P. Russell, J. H. Hou and H. Q. Zhou, A Highly Efficient NonFullerene Organic Solar Cell with a Fill Factor over 0.80 Enabled by a Fine-Tuned Hole-Transporting Layer, Adv. Mater., 2018, 30, 1801801.

98 J. Q. Wang, Z. Zheng, D. Y. Zhang, J. Q. Zhang, J. Y. Zhou, J. C. Liu, S. K. Xie, Y. Zhao, Y. Zhang, Z. X. Wei, J. H. Hou, Z. Y. Tang and H. Q. Zhou, Regulating Bulk-Heterojunction Molecular Orientations through Surface Free Energy Control of Hole-Transporting Layers for High-Performance Organic Solar Cells, Adv. Mater., 2019, 31, 1806921.

99 J. Noh, S. Jeong and J. Y. Lee, Ultrafast formation of airprocessable and high-quality polymer films on an aqueous substrate, Nat. Commun., 2016, 7, 12374.

100 C. Xie, T. Heumuller, W. Gruber, X. F. Tang, A. Classen, I. Schuldes, M. Bidwell, A. Spath, R. H. Fink, T. Unruh, I. McCulloch, N. Li and C. J. Brabec, Overcoming efficiency and stability limits in water-processing nanoparticular organic photovoltaics by minimizing microstructure defects, Nat. Commun., 2018, 9, 5335.

101 L. L. Sun, X. S. Jiang and Y. H. Zhou, Efficient nonfullerene organic solar cells with active layers fabricated by water transfer printing, J. Energy Chem., 2019, 37, 220-224.
102 X. Yang and J. Loos, Toward high-performance polymer solar cells: The importance of morphology control, Macromolecules, 2007, 40, 1353-1362.

103 J. Y. Park and R. C. Advincula, Nanostructuring polymers, colloids, and nanomaterials at the air-water interface through Langmuir and Langmuir-Blodgett techniques, Soft Matter, 2011, 7, 9829-9843.

104 J. X. Huang, F. Kim, A. R. Tao, S. Connor and P. D. Yang, Spontaneous formation of nanoparticle stripe patterns through dewetting, Nat. Mater., 2005, 4, 896-900.

105 W. D. Ristenpart, P. G. Kim, C. Domingues, J. Wan and H. A. Stone, Influence of substrate conductivity on circulation reversal in evaporating drops, Phys. Rev. Lett., 2007, 99, 234502.

106 C. Poulard and P. Damman, Control of spreading and drying of a polymer solution from Marangoni flows, $E P L$, 2007, 80, 64001.

107 A. H. Demond and A. S. Lindner, Estimation of InterfacialTension between Organic Liquids and Water, Environ. Sci. Technol., 1993, 27, 2318-2331.

108 F. J. M. Colberts, M. M. Wienk, R. Heuvel, W. W. Li, V. M. Corre, L. J. A. Koster and R. A. J. Janssen, BilayerTernary Polymer Solar Cells Fabricated Using Spontaneous Spreading on Water, Adv. Energy Mater., 2018, 8, 1802197.

109 N. Bhandaru, A. Karim and R. Mukherjee, Directed ordering of phase separated domains and dewetting of thin polymer blend films on a topographically patterned substrate, Soft Matter, 2017, 13, 4709-4719.

110 S. Steudel, S. De Vusser, S. De Jonge, D. Janssen, S. Verlaak, J. Genoe and P. Heremans, Influence of the dielectric roughness on the performance of pentacene transistors, Appl. Phys. Lett., 2004, 85, 4400-4402.

111 B. Stadlober, U. Haas, H. Maresch and A. Haase, Growth model of pentacene on inorganic and organic dielectrics based on scaling and rate-equation theory, Phys. Rev. B: Condens. Matter Mater. Phys., 2006, 74, 165302.

112 S. H. Lee, D. H. Kim, J. H. Kim, G. S. Lee and J. G. Park, Effect of Metal-Reflection and Surface-Roughness Properties on Power-Conversion Efficiency for Polymer Photovoltaic Cells, J. Phys. Chem. C, 2009, 113, 21915-21920.

113 Z. F. Ma, Z. Tang, E. G. Wang, M. R. Andersson, O. Inganas and F. L. Zhang, Influences of Surface Roughness of ZnO Electron Transport Layer on the Photovoltaic Performance of Organic Inverted Solar Cells, J. Phys. Chem. C, 2012, 116, 24462-24468.

114 H. R. Tseng, H. Phan, C. Luo, M. Wang, L. A. Perez, S. N. Patel, L. Ying, E. J. Kramer, T. Q. Nguyen, G. C. Bazan and A. J. Heeger, High-Mobility Field-Effect Transistors Fabricated with Macroscopic Aligned Semiconducting Polymers, Adv. Mater., 2014, 26, 2993-2998.

115 B. H. Lee, B. B. Y. Hsu, S. N. Patel, J. Labram, C. Luo, G. C. Bazan and A. J. Heeger, Flexible Organic Transistors with Controlled Nanomorphology, Nano Lett., 2016, 16, 314-319.

116 C. Luo, A. K. K. Kyaw, L. A. Perez, S. Patel, M. Wang, B. Grimm, G. C. Bazan, E. J. Kramer and A. J. Heeger, 
General Strategy for Self-Assembly of Highly Oriented Nanocrystalline Semiconducting Polymers with High Mobility, Nano Lett., 2014, 14, 2764-2771.

117 C. Kim, A. Facchetti and T. J. Marks, Polymer gate dielectric surface viscoelasticity modulates pentacene transistor performance, Science, 2007, 318, 76-80.

118 K. S. Nalwa, J. M. Park, K. M. Ho and S. Chaudhary, On Realizing Higher Efficiency Polymer Solar Cells Using a Textured Substrate Platform, Adv. Mater., 2011, 23, 112-116.

119 B. Agyei-Tuffour, N. Y. Doumon, E. R. Rwenyagila, J. Asare, O. K. Oyewole, Z. Shen, C. E. Petoukhoff, M. G. Z. Kana, D. M. Ocarroll and W. O. Soboyejo, Pressure effects on interfacial surface contacts and performance of organic solar cells, J. Appl. Phys., 2017, 122, 205501.

120 S. Jeong, C. Cho, H. Kang, K. H. Kim, Y. Yuk, J. Y. Park, B. J. Kim and J. Y. Lee, Nanoimprinting-Induced Nanomorphological Transition in Polymer Solar Cells: Enhanced Electrical and Optical Performance, ACS Nano, 2015, 9, 2773-2782.

121 Z. Li, K. H. Chiu, R. S. Ashraf, S. Fearn, R. Dattani, H. C. Wong, C. H. Tan, J. Y. Wu, J. T. Cabral and J. R. Durrant, Toward Improved Lifetimes of Organic Solar Cells under Thermal Stress: Substrate-Dependent Morphological Stability of PCDTBT:PCBM Films and Devices, Sci. Rep., 2015, 5, 15149.

122 S. Wang, B. M. Goh, K. K. Manga, Q. L. Bao, P. Yang and K. P. Loh, Graphene as Atomic Template and Structural Scaffold in the Synthesis of Graphene-Organic Hybrid Wire with Photovoltaic Properties, ACS Nano, 2010, 4, 6180-6186.

123 S. A. Mauger, L. L. Chang, S. Friedrich, C. W. Rochester, D. M. Huang, P. Wang and A. J. Moule, Self-Assembly of Selective Interfaces in Organic Photovoltaics, Adv. Funct. Mater., 2013, 23, 1935-1946.

124 J. W. Kingsley, P. P. Marchisio, H. Yi, A. Iraqi, C. J. Kinane, S. Langridge, R. L. Thompson, A. J. Cadby, A. J. Pearson, D. G. Lidzey, R. A. L. Jones and A. J. Parnell, Molecular weight dependent vertical composition profiles of PCDTBT: PC71BM blends for organic photovoltaics, Sci. Rep., 2014, 4, 5286.

125 Z. Xu, L. M. Chen, G. W. Yang, C. H. Huang, J. H. Hou, Y. Wu, G. Li, C. S. Hsu and Y. Yang, Vertical Phase Separation in Poly(3-hexylthiophene): Fullerene Derivative Blends and its Advantage for Inverted Structure Solar Cells, Adv. Funct. Mater., 2009, 19, 1227-1234.

126 L. M. Chen, Z. Xu, Z. R. Hong and Y. Yang, Interface investigation and engineering - achieving high performance polymer photovoltaic devices, J. Mater. Chem., 2010, 20, 2575.

127 Y. Yao, J. H. Hou, Z. Xu, G. Li and Y. Yang, Effect of solvent mixture on the nanoscale phase separation in polymer solar cells, Adv. Funct. Mater., 2008, 18, 1783-1789.

128 C. N. Hoth, P. Schilinsky, S. A. Choulis and C. J. Brabec, Printing highly efficient organic solar cells, Nano Lett., 2008, 8, 2806-2813.

129 K. Kawano, J. Sakai, M. Yahiro and C. Adachi, Effect of solvent on fabrication of active layers in organic solar cells based on poly(3-hexylthiophene) and fullerene derivatives, Sol. Energy Mater. Sol. Cells, 2009, 93, 514-518.
130 J. J. van Franeker, M. Turbiez, W. W. Li, M. M. Wienk and R. A. J. Janssen, A real-time study of the benefits of co-solvents in polymer solar cell processing, Nat. Commun., 2015, 6, 6229.

131 J. Peet, J. Y. Kim, N. E. Coates, W. L. Ma, D. Moses, A. J. Heeger and G. C. Bazan, Efficiency enhancement in low-bandgap polymer solar cells by processing with alkane dithiols, Nat. Mater., 2007, 6, 497-500.

132 Y. Gu, C. Wang and T. P. Russell, Multi-Length-Scale Morphologies in PCPDTBT/PCBM Bulk-Heterojunction Solar Cells, Adv. Energy Mater., 2012, 2, 683-690.

133 J. Peet, N. S. Cho, S. K. Lee and G. C. Bazan, Transition from Solution to the Solid State in Polymer Solar Cells Cast from Mixed Solvents, Macromolecules, 2008, 41, 8655-8659.

134 B. M. Xie, K. Zhang, Z. C. Hu, H. Y. Fang, B. J. Lin, Q. W. Yin, B. T. He, S. Dong, L. Ying, W. Ma, F. Huang, H. Yan and Y. Cao, Polymer Pre-Aggregation Enables Optimal Morphology and High Performance in All-Polymer Solar Cells, Sol. RRL, 2020, 4, 1900385.

135 Z. Y. Li, L. Ying, P. Zhu, W. K. Zhong, N. Li, F. Liu, F. Huang and Y. Cao, A generic green solvent concept boosting the power conversion efficiency of all-polymer solar cells to 11\%, Energy Environ. Sci., 2019, 12, 157-163.

136 F. Liu, W. Zhao, J. R. Tumbleston, C. Wang, Y. Gu, D. Wang, A. L. Briseno, H. Ade and T. P. Russell, Understanding the Morphology of PTB7: PCBM Blends in Organic Photovoltaics, Adv. Energy Mater., 2014, 4, 1301377.

137 F. Liu, Y. Gu, C. Wang, W. Zhao, D. Chen, A. L. Briseno and T. P. Russell, Efficient Polymer Solar Cells Based on a Low Bandgap Semi-crystalline DPP Polymer-PCBM Blends, Adv. Mater., 2012, 24, 3947-3951.

138 Q. Wan, X. Guo, Z. Y. Wang, W. B. Li, B. Guo, W. Ma, M. J. Zhang and Y. F. Li, 10.8\% Efficiency Polymer Solar Cells Based on PTB7-Th and PC71BM via Binary Solvent Additives Treatment, Adv. Funct. Mater., 2016, 26, 6635-6640.

139 L. A. Perez, K. W. Chou, J. A. Love, T. S. van der Poll, D. M. Smilgies, T. Q. Nguyen, E. J. Kramer, A. Amassian and G. C. Bazan, Solvent Additive Effects on Small Molecule Crystallization in Bulk Heterojunction Solar Cells Probed During Spin Casting, Adv. Mater., 2013, 25, 6380-6384.

140 S. J. Lou, J. M. Szarko, T. Xu, L. P. Yu, T. J. Marks and L. X. Chen, Effects of Additives on the Morphology of Solution Phase Aggregates Formed by Active Layer Components of High-Efficiency Organic Solar Cells, J. Am. Chem. Soc., 2011, 133, 20661-20663.

141 T. S. van der Poll, J. A. Love, T. Q. Nguyen and G. C. Bazan, Non-Basic High-Performance Molecules for SolutionProcessed Organic Solar Cells, Adv. Mater., 2012, 24, 3646-3649.

142 J. Peet, C. Soci, R. C. Coffin, T. Q. Nguyen, A. Mikhailovsky, D. Moses and G. C. Bazan, Method for increasing the photoconductive response in conjugated polymer/fullerene composites, Appl. Phys. Lett., 2006, 89, 252105. 
143 J. K. Lee, W. L. Ma, C. J. Brabec, J. Yuen, J. S. Moon, J. Y. Kim, K. Lee, G. C. Bazan and A. J. Heeger, Processing additives for improved efficiency from bulk heterojunction solar cells, J. Am. Chem. Soc., 2008, 130, 3619-3623.

144 H. C. Liao, C. S. Tsao, Y. T. Shao, S. Y. Chang, Y. C. Huang, C. M. Chuang, T. H. Lin, C. Y. Chen, C. J. Su, U. S. Jeng, Y. F. Chen and W. F. Su, Bi-hierarchical nanostructures of donor-acceptor copolymer and fullerene for high efficient bulk heterojunction solar cells, Energy Environ. Sci., 2013, 6, 1938-1948.

145 C. V. Hoven, X. D. Dang, R. C. Coffin, J. Peet, T. Q. Nguyen and G. C. Bazan, Improved Performance of Polymer Bulk Heterojunction Solar Cells Through the Reduction of Phase Separation via Solvent Additives, Adv. Mater., 2010, 22, E63-E66.

146 K. Schmidt, C. J. Tassone, J. R. Niskala, A. T. Yiu, O. P. Lee, T. M. Weiss, C. Wang, J. M. J. Frechet, P. M. Beaujuge and M. F. Toney, A Mechanistic Understanding of Processing Additive-Induced Efficiency Enhancement in Bulk Heterojunction Organic Solar Cells, Adv. Mater., 2014, 26, 300-305.

147 H. Choi, S. J. Ko, T. Kim, P. O. Morin, B. Walker, B. H. Lee, M. Leclerc, J. Y. Kim and A. J. Heeger, Small-Bandgap Polymer Solar Cells with Unprecedented Short-Circuit Current Density and High Fill Factor, Adv. Mater., 2015, 27, 3318-3324.

148 Z. H. Yang, Y. C. Guo, H. F. Li, Y. C. Zhou, X. H. Zuo, Y. J. Yu, C. Pan, J. Strzalka, C. Y. Nam and M. H. Rafailovich, Roles of Interfacial Tension in Regulating Internal Organization of Low Bandgap Polymer Bulk Heterojunction Solar Cells by Polymer Additives, Adv. Mater. Interfaces, 2018, 5, 1800435.

149 Z. Z. Sun, K. Xiao, J. K. Keum, X. Yu, K. L. Hong, J. Browning, I. N. Ivanov, J. H. Chen, J. Alonzo, D. W. Li, B. G. Sumpter, E. A. Payzant, C. M. Rouleau and D. B. Geohegan, PS- $b$-P3HT Copolymers as P3HT/PCBM Interfacial Compatibilizers for High Efficiency Photovoltaics, Adv. Mater., 2011, 23, 5529-5535.

150 K. R. Graham, J. G. Mei, R. Stalder, J. W. Shim, H. Cheun, F. Steffy, F. So, B. Kippelen and J. R. Reynolds, Polydimethylsiloxane as a Macromolecular Additive for Enhanced Performance of Molecular Bulk Heterojunction Organic Solar Cells, ACS Appl. Mater. Interfaces, 2011, 3, 1210-1215.

151 Z. X. Wei, Achieving over 13\% Power Conversion Efficiency in Organic Solar Cells, Acta Phys.-Chim. Sin., 2017, 33, 2119-2120.

152 S. Q. Zhang and J. H. Hou, Rational Design Strategies for Polymer Donors for Applications in Non-Fullerene Organic Photovoltaic Cells, Acta Phys.-Chim. Sin., 2017, 33, 2327-2338.

153 J. Chen, Z. Bi, X. Xu, Q. Zhang, S. Yang, S. Guo, H. Yan, W. You and W. Ma, Fine Optimization of Morphology Evolution Kinetics with Binary Additives for Efficient Non-Fullerene Organic Solar Cells, Adv. Sci., 2019, 6, 1801560.
154 B. Huang, L. Hu, L. Chen, S. Chen, M. Hu, Y. Zhou, Y. Zhang, C. Yang and Y. Chen, Morphological optimization by rational matching of the donor and acceptor boosts the efficiency of alkylsilyl fused ring-based polymer solar cells, J. Mater. Chem. A, 2019, 7, 4847-4854.

155 W. L. Ma, C. Y. Yang, X. Gong, K. Lee and A. J. Heeger, Thermally stable, efficient polymer solar cells with nanoscale control of the interpenetrating network morphology, Adv. Funct. Mater., 2005, 15, 1617-1622.

156 Y. Kim, S. A. Choulis, J. Nelson, D. D. C. Bradley, S. Cook and J. R. Durrant, Device annealing effect in organic solar cells with blends of regioregular poly(3-hexylthiophene) and soluble fullerene, Appl. Phys. Lett., 2005, 86, 063502.

157 X. N. Yang, J. Loos, S. C. Veenstra, W. J. H. Verhees, M. M. Wienk, J. M. Kroon, M. A. J. Michels and R. A. J. Janssen, Nanoscale morphology of high-performance polymer solar cells, Nano Lett., 2005, 5, 579-583.

158 C. V. Kumar, L. Cabau, A. Viterisi, S. Biswas, G. D. Sharma and E. Palomares, Solvent Annealing Control of Bulk Heterojunction Organic Solar Cells with 6.6\% Efficiency Based on a Benzodithiophene Donor Core and Dicyano Acceptor Units, J. Phys. Chem. C, 2015, 119, 20871-20879.

159 S. Grob, A. N. Bartynski, A. Opitz, M. Gruber, F. Grassl, E. Meister, T. Linderl, U. Hormann, C. Lorch, E. Moons, F. Schreiber, M. E. Thompson and W. Brutting, Solvent vapor annealing on perylene-based organic solar cells, J. Mater. Chem. A, 2015, 3, 15700-15709.

160 G. Li, Y. Yao, H. Yang, V. Shrotriya, G. Yang and Y. Yang, Solvent annealing effect in polymer solar cells based on poly(3-hexylthiophene) and methanofullerenes, Adv. Funct. Mater., 2007, 17, 1636-1644.

161 T. Erb, U. Zhokhavets, G. Gobsch, S. Raleva, B. Stuhn, P. Schilinsky, C. Waldauf and C. J. Brabec, Correlation between structural and optical properties of composite polymer/fullerene films for organic solar cells, Adv. Funct. Mater., 2005, 15, 1193-1196.

162 C. V. Thompson, Secondary grain growth in thin films of semiconductors: Theoretical aspects, J. Appl. Phys., 1985, 58, 763-772.

163 M. Campoy-Quiles, T. Ferenczi, T. Agostinelli, P. G. Etchegoin, Y. Kim, T. D. Anthopoulos, P. N. Stavrinou, D. D. C. Bradley and J. Nelson, Morphology evolution via self-organization and lateral and vertical diffusion in polymer: fullerene solar cell blends, Nat. Mater., 2008, 7, 158-164.

164 D. Bharti, V. Raghuwanshi, I. Varun, A. K. Mahato and S. P. Tiwari, Directional Solvent Vapor Annealing for Crystal Alignment in Solution-Processed Organic Semiconductors, ACS Appl. Mater. Interfaces, 2017, 9, 26226-26233.

165 D. Zomerman, J. Kong, S. M. McAfee, G. C. Welch and T. L. Kelly, Control and Characterization of Organic Solar Cell Morphology Through Variable-Pressure Solvent Vapor Annealing, ACS Appl. Energy Mater., 2018, 1, 5663-5674.

166 R. Datt, Suman, A. Bagui, A. Siddiqui, R. Sharma, V. Gupta, S. Yoo, S. Kumar and S. P. Singh, Effectiveness of Solvent Vapor Annealing over Thermal Annealing on the 
Photovoltaic Performance of Non-Fullerene Acceptor Based BHJ Solar Cells, Sci. Rep., 2019, 9, 8529.

167 J. L. Wang, K. K. Liu, J. Yan, Z. Wu, F. Liu, F. Xiao, Z. F. Chang, H. B. Wu, Y. Cao and T. P. Russell, Series of Multifluorine Substituted Oligomers for Organic Solar Cells with Efficiency over $9 \%$ and Fill Factor of 0.77 by Combination Thermal and Solvent Vapor Annealing, J. Am. Chem. Soc., 2016, 138, 7687-7697.
168 S. Nam, J. Jang, H. Cha, J. Hwang, T. K. An, S. Park and C. E. Park, Effects of direct solvent exposure on the nanoscale morphologies and electrical characteristics of PCBM-based transistors and photovoltaics, J. Mater. Chem., 2012, 22, 5543-5549.

169 Y. F. Zheng, S. G. Li, D. Zheng and J. S. Yu, Effects of different polar solvents for solvent vapor annealing treatment on the performance of polymer solar cells, Org. Electron., 2014, 15, 2647-2653. 